\title{
Article \\ Quantum-Chemical Search for Keto Tautomers of Azulenols in Vacuo and Aqueous Solution
}

\author{
Ewa D. Raczyńska
}

Citation: Raczyńska, E.D.

Quantum-Chemical Search for Keto

Tautomers of Azulenols in Vacuo and Aqueous Solution. Symmetry 2021, 13 , 497. https://doi.org/10.3390/ sym13030497

Academic Editor: Edwin

Charles Constable

Received: 1 March 2021

Accepted: 16 March 2021

Published: 18 March 2021

Publisher's Note: MDPI stays neutral with regard to jurisdictional claims in published maps and institutional affiliations.

Copyright: (C) 2021 by the author. Licensee MDPI, Basel, Switzerland. This article is an open access article distributed under the terms and conditions of the Creative Commons Attribution (CC BY) license (https:// creativecommons.org/licenses/by/ $4.0 /)$.
Department of Chemistry, Warsaw University of Life Sciences (SGGW), ul. Nowoursynowska 159c, 02-776 Warszawa, Poland; ewa_raczynska@sggw.edu.pl; Tel.: +48-22-59-37623

\begin{abstract}
Keto-enol prototropic conversions for carbonyl compounds and phenols have been extensively studied, and many interesting review articles and even books appeared in the last 50 years. Quite a different situation takes place for derivatives of biologically active azulene, for which only scanty information on this phenomenon can be found in the literature. In this work, quantumchemical studies have been undertaken for symmetrically and unsymmetrically substituted azulenols (constitutional isomers of naphthols). Stabilities of two enol $(\mathrm{OH})$ rotamers and all possible keto $(\mathrm{CH})$ tautomers have been analyzed in the gas phase $\{\mathrm{DFT}(\mathrm{B} 3 \mathrm{LYP}) / 6-311+\mathrm{G}(\mathrm{d}, \mathrm{p})\}$ and also in aqueous solution $\{\mathrm{PCM}($ water $) / / \mathrm{DFT}(\mathrm{B} 3 \mathrm{LYP}) / 6-311+\mathrm{G}(\mathrm{d}, \mathrm{p})\}$. Contrary to naphthols, for which the keto forms can be neglected, at least one keto isomer $(\mathrm{C} 1 \mathrm{H}, \mathrm{C} 2 \mathrm{H}$, and/or $\mathrm{C} 3 \mathrm{H})$ contributes significantly to the tautomeric mixture of each azulenol to a higher degree in vacuo (non-polar environment) than in water (polar amphoteric solvent). The highest amounts of the $\mathrm{CH}$ forms have been found for 2- and 5-hydroxyazulenes, and the smallest ones for 1- and 6-hydroxy derivatives. The keto tautomer(s), together with the enol rotamers, can also participate in deprotonation reaction leading to a common anion and influence its acid-base properties. The strongest acidity in vacuo exhibits 6-hydroxyazulene, and the weakest one displays 1-hydroxyazulene, but all azulenols are stronger acids than phenol and naphthols. Bond length alternation in all DFT-optimized structures has been measured using the harmonic oscillator model of electron delocalization (HOMED) index. Generally, the HOMED values decrease for the keto tautomers, particularly for the ring containing the labile proton. Even for the keto tautomers possessing energetic parameters close to those of the enol isomers, the HOMED indices are low. However, some kind of parallelism exists for the keto forms between their relative energies and HOMEDs estimated for the entire molecules.
\end{abstract}

Keywords: hydroxyazulenes and their anions; electron delocalization; HOMED indices; keto tautomers; solvent effect; acid-base properties; quantum-chemical guest

\section{Introduction}

Owing to remarkable physicochemical properties and biological activities, azulene and its derivatives have attracted the particular attention of many theoretical and experimental researchers for more than two hundred years [1-4]. Numerous interesting chromophores, particularly colorful pigments, possessing the azulene skeleton have been identified in various herbal plants, e.g., chamomile, wormwood, guaiac wood, yarrow, etc. [5-7]. Colorful azulenoids have also been detected in mushrooms [8] and marine invertebrates [9]. Azulene-hydrocarbons (sesquiterpenes) and their derivatives can be employed as dye materials. Their color depends on the nature and position of the substituent(s) introduced at carbon atom(s) [10,11]. Azulenes display interesting biological activities such as antifungal, antibacterial, antiviral, antimicrobial, antioxidative, antitumor, etc. [8,12-18]. Some of them are used in many skincare and cosmetic products [18]. Due to remarkable polarizability of the azulene system, its derivatives show promising applications in the design of new organic superbases [19]. They can also be used as advanced organic materials (organic metals, liquid crystals, polymers, nonlinear optical chromophores, solar cells, etc.) $[2-4,20-24]$. 
Similar to its valence isomer naphthalene, azulene contains two rings and 10 delocalized $\pi$-electrons (Figure 1). These rings, however, consist of a different number of $\mathrm{C}$ atoms [25]. In azulene, five-membered cyclopentadiene is structurally fused with sevenmembered cycloheptatriene, whereas in naphthalene, two six-membered benzene fragments are structurally fused together. Consequently, the two isomers have not only different structures but also exhibit different physicochemical properties [1,25-28]. For example, naphthalene is a non-polar and colorless compound, while azulene is a polar and dark blue substance. The large dipole moment of azulene can be explained by the Hückel molecular orbital theory [26]. Because of its high polarity and polarizability, azulene exhibits higher proton and lithium-cation basicity in the gas phase than naphthalene [27,28]. Its gas-phase acidity is also stronger than that of its isomer [27]. Moreover, naphthalene mainly gives products of electrophilic substitution, except for some particular derivatives, whereas azulene can react with both electrophiles and nucleophiles $[29,30]$.

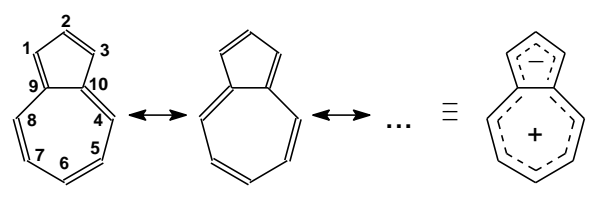

(a)

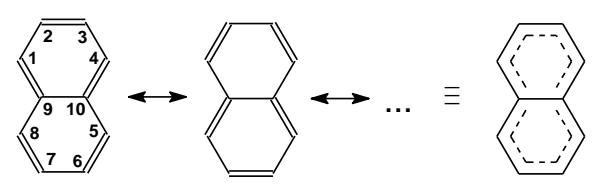

(b)

Figure 1. The structural differences between azulene (a) and naphthalene (b).

Taking these remarkable properties of azulene and its derivatives into account, and only a few articles on an exciting phenomenon (prototropic tautomerism) occurring in some derivatives, we concentrated our attention in this work on azulenols (monohydroxyazulenes) that can exist in various keto and enol forms. For some of their derivatives, such as 2-hydroxyazulene, 6-hydroxyazulene, and 6-hydroxy-4,8-dimethylazulene, symmetrically substituted by one $\mathrm{OH}$ group, unsymmetrically mono-substituted 1-hydroxyazulene, and symmetrically disubstituted 2,6-dihydroxyazulene, syntheses have already been reported, and some keto and/or enol tautomers experimentally identified [31-34]. Using nuclear magnetic resonance (NMR) and infrared (IR) techniques, the single enol form has been detected mainly in acetone- $\mathrm{d}_{6}$, whereas some keto isomers have been found in chloroform-d [31-34].

To our knowledge, there are no data on keto-enol equilibria for hydroxyazulenes in the gas phase and aqueous solution. Taking the experimental NMR and IR results for some derivatives into account [31-34], we applied here quantum-chemical methods to isolated and hydrated azulenes containing one $\mathrm{OH}$ group at 1-, 2-, 4-, 5-, and 6-position (AH1-AH5, given in Figure 2). In this way, the stability and bond lengths alternation of enol rotamers and of all possible keto tautomers for AH1-AH5 could be analyzed in detail, and the structures indicated for favored isomers that mainly consist of tautomeric mixtures in two extreme environments, vacuo and water. For estimation of their acid-base strength, the corresponding conjugate anions $\left(\mathbf{A}^{-} \mathbf{1}^{-} \mathbf{A}^{-} \mathbf{5}\right)$ have also been considered, and thermochemistry of deprotonation-protonation reaction $\left(\mathrm{AH} \rightleftarrows \mathbf{A}^{-}+\mathrm{H}^{+}\right)$investigated for individual isomers as well as for isomeric mixtures. Since $\mathrm{p} K_{\mathrm{a}}$ of some azulenols have been reported [32], their acidities have been estimated in the gas phase and compared with those of phenol and naphthols. 


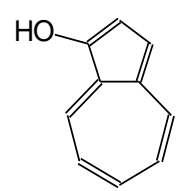

AH1<smiles></smiles>

AH2

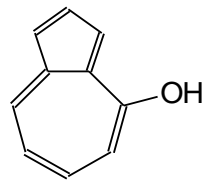

AH3

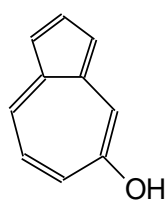

AH4

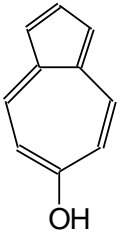

AH5

Figure 2. Monohydroxyazulenes investigated in this work.

Note that only major and minor isomers can be identified when experimental techniques are used. Usually, rare isomers $(<0.1 \%)$ can be difficult to find in the background, and experimental techniques (e.g., IR or NMR) do not give the complete picture on prototropy in tautomeric systems [31-34]. Contrary to the experimental methods, quantum-chemical calculations cannot be limited to the favored forms. All isomers, even those considered as very rare forms $(<0.001 \%)$, can be investigated, and their structures, stabilities, and some physicochemical properties established. Such kind of information is essential in studies on derivatives of interesting properties and activities.

\section{Methodology}

Two levels of theory have been employed to study the keto and enol isomers of five hydroxyazulenes (AH1-AH5): the density functional theory (DFT) method [35] with the Becke three-parameter hybrid exchange functional and non-local correlation functional of Lee, Yang, and Par (B3LYP) [36,37] and the 6-311+G(d,p) basis set [38], and the polarizable continuum model (PCM) theory [39,40]. The choice of these quantum-chemical methods for the investigation of proton-transfer processes (including prototropic conversions) in isolated and hydrated systems has been discussed in our earlier works [41,42]. First, the stabilities of all possible isomers of AH1-AH5 have been investigated in vacuo at the DFT(B3LYP) /6$311+G(d, p)$ level. Their Lewis structures are given in Figure $S 1$ in the Supplementary Materials. Next, calculations have been carried out at the PCM(water)//DFT(B3LYP)/6-311+G(d,p) level. The PCM parameters are included in the Supplementary Materials. In both cases, no restriction has been applied to the geometry optimization in the ground states. In this way, small structural and thermochemical changes in isomeric mixtures when proceeding from the gas phase to aqueous solution could be observed. The atom coordinates for the isolated and hydrated structures of all possible neutral AH1-AH5 isomers optimized in vacuo $\{\mathrm{DFT}(\mathrm{B} 3 \mathrm{LYP}) / 6-311+\mathrm{G}(\mathrm{d}, \mathrm{p})\}$ and aqueous solution $\{\mathrm{PCM}($ water $) / / \mathrm{DFT}(\mathrm{B} 3 \mathrm{LYP}) / 6-$ $311+G(d, p)\}$, respectively, are summarized in Table S1 (Supplementary Materials). Their electronic energies $(E)$ calculated at the two levels of theory are included in Table S2 (Supplementary Materials). Geometric and energetic parameters for deprotonated forms of azulenols $\left(\mathbf{A}^{-} \mathbf{1}_{-} \mathbf{A}^{-} \mathbf{5}\right)$ have been estimated in the gas phase at the DFT(B3LYP)/6$311+G(d, p)$ level in their ground states. The atom coordinates for the five anion structures and their electronic energies are listed in Table S3 (Supplementary Materials). For all calculations, the Gaussian 03 series of programs [43] has been applied.

The harmonic oscillator model of electron delocalization (HOMED) indices [44], based on the original HOMA (harmonic oscillator model of aromaticity) procedure [45], have been calculated according to Equation (1) for the DFT-optimized structures of AH1-AH5 and $\mathbf{A}^{-} \mathbf{1}-\mathbf{A}^{-} \mathbf{5}$. For each structure, HOMEDs have been determined for the five- and seven-membered rings, azulene skeleton, and entire molecule, and abbreviated here as HOMED5, HOMED7, HOMED11, and HOMED12, respectively. For comparison, HOMEDs have also been estimated for the parent azulene, its valence isomer naphthalene, and their aromatic cyclic parts (cyclopentadiene anion, cycloheptatriene cation, and benzene). Their structures have been optimized at the same DFT level.

$$
\text { HOMED }=1-\left\{\alpha(\mathrm{CC}) \Sigma\left[R_{\mathrm{O}}(\mathrm{CC})-R_{\mathrm{X}}(\mathrm{CC})\right]^{2}+\alpha(\mathrm{CO}) \Sigma\left[R_{\mathrm{o}}(\mathrm{CO})-R_{\mathrm{X}}(\mathrm{CO})\right]^{2}\right\} / n
$$


Parameters $\alpha(\mathrm{CC}), \alpha(\mathrm{CO}), R_{\mathrm{O}}(\mathrm{CC}), R_{\mathrm{O}}(\mathrm{CO}), R_{\mathrm{x}}$, and $n$, applied in Equation (1), are the normalization constants for $\mathrm{CC}$ and $\mathrm{CO}$ bonds, optimum $\mathrm{CC}$ and $\mathrm{CO}$ bond lengths for the reference molecules $\left\{\mathrm{C}_{6} \mathrm{H}_{5}\right.$ and $\left.{ }^{+} \mathrm{C}(\mathrm{OH})_{3}\right\}$, bond lengths for investigated compounds, and number of bonds $(5,7,11$, and 12$)$ in a considered part of investigated systems, respectively. The following values have been used for the CC and CO bonds [44]: $R_{\mathrm{O}}(\mathrm{CC})=1.3943$ $\AA, R_{\mathrm{o}}(\mathrm{CO})=1.2811 \AA, \alpha_{5}(\mathrm{CC})=78.34, \alpha_{7}(\mathrm{CC})=80.90, \alpha_{11}(\mathrm{CC})=83.37, \alpha_{12}(\mathrm{CC})=88.09$, and $\alpha_{12}(\mathrm{CO})=75.00$, all of them estimated at the same level of theory $\{\mathrm{DFT}(\mathrm{B} 3 \mathrm{LYP} / 6-$ $311+G(d, p)\}$ as that employed for the azulene derivatives.

Vibrational frequencies have been calculated for selected structures of neutral AH1AH5 isomers and for their anions $\mathbf{A}^{-} \mathbf{1}-\mathbf{A}^{-} \mathbf{5}$ using the same DFT(B3LYP)/6-311+G(d,p) level. Calculations confirmed that the optimized structures refer to the energy minima with real frequencies. Thermochemical quantities such as the enthalpy $(H=E+p V)$, entropy (S), and Gibbs energy ( $G=H-T S$ for $T=298.15 \mathrm{~K}$ ) have been calculated for all selected species. Their $H$ and $G$ values are summarized in Table S4 (Supplementary Materials). The relative Gibbs energies $(\Delta G)$ have been determined for the isolated and hydrated enol rotamers and keto tautomers. They are given in Table S5 (Supplementary Materials). For each hydroxyazulene, the composition of the isomeric mixture has been estimated on the basis of the $\Delta G$ values calculated for all potential keto and enol isomers using Equation (2), where $x$ is the isomer mole-fraction.

$$
x \approx\{\exp (-\Delta G / R T)\} /\{\Sigma[\exp (-\Delta G / R T)]\}
$$

For the reversible deprotonation-protonation reaction in the gas phase, $\mathbf{A H} \rightleftarrows \mathbf{A}^{-}+$ $\mathrm{H}^{+}$, basicity quantities for the anion $\mathrm{A}^{-}$such as negative protonation energy $\left(-E_{\text {prot }}\right)$ at $0 \mathrm{~K}$, proton affinity (PA), and gas-phase basicity (GB) at $298 \mathrm{~K}$ have been determined by applying Equations (3)-(5), respectively [27]. In Equations (3)-(5), $\left.\mathrm{H}_{(\mathrm{H}}{ }^{+}\right)=6.2 \mathrm{~kJ} \mathrm{~mol}^{-1}$, and $G\left(\mathrm{H}^{+}\right)=-26.3 \mathrm{~kJ} \mathrm{~mol}^{-1}[46], E, H$, and $G$ correspond to the electronic energy at $0 \mathrm{~K}$, enthalpy, and Gibbs energy at $298 \mathrm{~K}$ calculated for the corresponding neutral azulenol AH and its anionic $\mathbf{A}^{-}$form, respectively (Tables S2-S4 in Supplementary Materials). In the gas phase, $-E_{\text {prot }}$, PA, and GB for $\mathbf{A}^{-}$are equal to the corresponding acidity parameters for $\mathbf{A H}$ in the electronic energy, enthalpy, and Gibbs energy scales, respectively. The $-E_{\text {prot }}$ values have been estimated for each possible conjugated site of protonation in anion derivatives. PAs and GBs have been calculated for the major and minor isomers of tautomeric systems as well as for their mixtures.

$$
\begin{gathered}
-E_{\text {prot }}=E\left(\mathbf{A}^{-}\right)-E(\mathbf{A H}) \\
\mathrm{PA}=H\left(\mathbf{A}^{-}\right)+H\left(\mathrm{H}^{+}\right)-H(\mathbf{A H}) \\
\mathrm{GB}=G\left(\mathbf{A}^{-}\right)+G\left(\mathrm{H}^{+}\right)-G(\mathbf{A H})
\end{gathered}
$$

\section{Results and Discussion}

\subsection{Deprotonated Forms of Hydroxyazulenes}

Deprotonation of five hydroxyazulenes (AH1-AH5) leads to five deprotonated forms $\left(\mathbf{A}^{-} \mathbf{1}-\mathbf{A}^{-} \mathbf{5}\right)$. On the basis of our DFT calculations carried out for anions, one can conclude that $\mathbf{A}^{-} \mathbf{5}$ with the exo $\mathrm{O}^{-}$group at 6-position possesses the lowest electronic energy, while $\mathbf{A}^{-1} \mathbf{1}$ containing this group at 1-position has the highest one (Table S3 in Supplementary Materials). The relative electronic energies ( $\Delta E$ in parentheses, in $\left.\mathrm{kJ} \mathrm{mol}^{-1}\right)$ increase for anions in the following order: $\mathbf{A}^{-} \mathbf{5}(0.0)<\mathbf{A}^{-} \mathbf{3}(7.7)<\mathbf{A}^{-} \mathbf{2}(24.0)<\mathbf{A}^{-4}(46.7)<\mathbf{A}^{-} \mathbf{1}$ (71.3). The same is true for their relative Gibbs energies $(\Delta G)$. The order of $\Delta G$ is the same as that of $\Delta E$. The $\Delta E$ order for anions, however, is not totally analogous to that found at the same level of theory for the favorable conformations of the neutral enol forms (Table S2 in Supplementary Materials): AH3 (0.0) < AH2 (4.6) $\approx$ AH5 (4.8) < AH4 (19.0) < AH1 (24.2). This suggests that the effects of the exo $\mathrm{O}^{-}$and $\mathrm{OH}$ groups on stability of the anion and neutral forms are not exactly parallel, probably because of some differences 
in intramolecular interactions. Nevertheless, the order of electronic (or Gibbs) energies found for anions dictates the acid-base strength of investigated azulenols (see below the DFT-estimated PAs and GBs for the isomeric mixtures of AH1-AH5).

The deprotonated forms of azulenols $\mathbf{A}^{-} \mathbf{1}_{-} \mathbf{A}^{-} \mathbf{5}$ contain one negative charge, three pairs of n-electrons, and $10 \pi$-electrons that can be more or less delocalized in the azulene skeleton. To show the differences in delocalization of the charge and electrons for anions, various potential resonance structures can be written (Figure 3). Among them, one structure with the negative charge placed on the exo $\mathrm{O}$ atom and also the other ones with the negative charge on the endo $C$ atoms can be considered. As we can see, the number of the potential resonance structures is not always the same for anions, and the negative charge is not always delocalized on the same endo $C$ atoms. Depending on the position of the exo $\mathrm{O}^{-}$group, different endo $\mathrm{C}$ atoms ( $\mathrm{n}-\pi$ conjugated with this group) can delocalize the negative charge. For example, the exo $\mathrm{O}^{-}$group at 1-position is conjugated with eight endo $\mathrm{C}$ atoms: $\mathrm{C} 2, \mathrm{C} 4, \mathrm{C} 5, \mathrm{C} 6, \mathrm{C} 7, \mathrm{C} 8, \mathrm{C}$, and $\mathrm{C} 10$. The exo $\mathrm{O}^{-}$group at 2- or 5-position is conjugated with five endo $\mathrm{C}$ atoms: $\mathrm{C} 1, \mathrm{C} 3, \mathrm{C} 4, \mathrm{C} 6$, and $\mathrm{C} 8$. The exo $\mathrm{O}^{-}$group at 4- or 6-position is conjugated with seven endo $C$ atoms: $C 1, C 2, C 3, C 5, C 7, C 9$, and C10. These variations in the negative-charge delocalization and the number of resonance structures evidently reveal differences in protonation reaction of $\mathbf{A}^{-} \mathbf{1}^{-} \mathbf{A}^{-}$. . The proton can be linked not only to the $\mathrm{O}$ atom but also to the selected (conjugated) $\mathrm{C}$ atoms, both being in different positions for different anions. Consequently, the number of possible keto tautomers for hydroxyazulenes AH1-AH5 are different and correspond to the number of conjugated sites (see below).

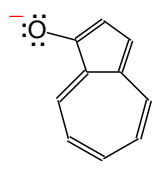

A-1-1

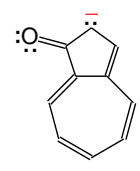

A-1-2<smiles>O=C1CCC23CC=CC=CC12CC3</smiles>

A-1-3

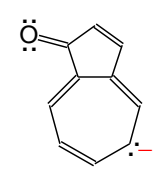

A-1-4<smiles>O=C1CCC2CC=CCC12</smiles>

A-1-5

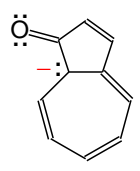

A-1-6

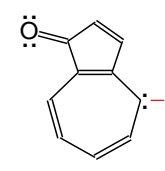

A-1-7<smiles>O=C1CCC2C3CCCC(CC3)C12</smiles>

A-1-8

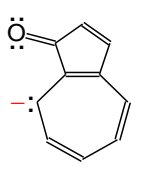

A-1-9

(a)<smiles>[O-]C1CCC2CCCCC2C1</smiles><smiles>O=C1CC2CCCCC2C1</smiles><smiles>CC1CCCCC2CC(O)CC12</smiles>

A-2-3

A-2-4

A-2-5

A-2-6

(b)<smiles>O=C1C=CCCC2CCCC12</smiles><smiles>O=C1C=CCCC2CCCC12</smiles><smiles>O=C1CCCCC2CCCC12</smiles><smiles>O=C1C=CCC=C2CCCC12</smiles><smiles>O=C1C=CC=CC2CCCC12</smiles><smiles>O=C1CCCC=C2CCCC12</smiles>

A-3-5

A-3-6

A-3-7

(c)

Figure 3. Cont. 
<smiles>[O-]c1cccc2cccc-2c1</smiles><smiles>O=C1C=CC=C2C=CCC2[C-]1F</smiles>

A-4-2<smiles>O=C1C=CC2CC=CC2=CC1</smiles>

A-5-2<smiles>O=C1C=CC2C=CCC2C=C1</smiles>

A-5-3<smiles></smiles>

A-4-3<smiles>O=C1C=CC2C=CCC2C=C1</smiles>

A-5-4<smiles></smiles>

A-4-4

(d)<smiles>CC12C=CC=C1C=CC(=O)C=C2</smiles>

A-5-5
A-4-5

A-4-6<smiles>O=C1C=CC(Cl)C2=CC=CC2=C1</smiles><smiles>O=c1cccc2c(c1)C=CC2</smiles><smiles>O=C1C=CC2C=CC(=O)C2C=C1</smiles><smiles>O=c1ccc2ccsc2cc1</smiles>

A-5-7

(e)

Figure 3. The potential resonance structures for anions of hydroxyazulenes: $\mathbf{A}^{-1} \mathbf{1}(\mathbf{a}), \mathbf{A}^{-} \mathbf{2}(\mathbf{b}), \mathbf{A}^{-} \mathbf{3}(\mathbf{c}), \mathbf{A}^{-} \mathbf{4}(\mathbf{d})$, and $\mathbf{A}^{-} \mathbf{5}$ (e).

According to the Brønsted-Lowry theory, the protonation of the most basic anionic site in the tautomeric system usually leads to the favored tautomer. In other words, the less-acidic tautomer predominates in the mixture. In Figure 4, the DFT-estimated negative protonation energies ( $-E_{\text {prot }}$ ) calculated according to Equation (3) for the $n-\pi$ conjugated basic sites in $\mathbf{A}^{-} \mathbf{1}-\mathbf{A}^{-} \mathbf{5}$ are included. Our results confirm that the exo $\mathrm{O}^{-}$group is the most basic site in all derivatives studied here. For this group, the highest $-E_{\text {prot }}$ values are found. The exo $\mathrm{O}^{-}$group binds preferentially to the proton in protonation reaction and form the favored enol form. Note that two enol structures and two negative protonation energies are possible for the $\mathrm{O}$ atom. The two enol forms can be favored in the tautomeric mixture. Interestingly, the $\mathrm{C} 1$ and $\mathrm{C} 3$ atoms in $\mathbf{A}^{-2}$ and $\mathbf{A}^{-4} \mathbf{4}$ display basicities very close (or even equal) to those of the exo $\mathrm{O}^{-}$group, indicating that the keto forms can also be found in significant amounts in the isomeric mixtures of AH2 and AH4. Note that differences in the negative protonation energies of the conjugated $\mathrm{O}^{-}$and $\mathrm{C}^{-}$sites in the anionic forms determine differences in the electronic energies between the corresponding enol and keto isomers.

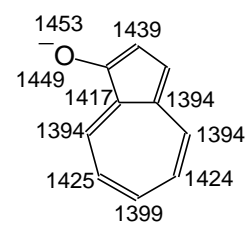

A-1

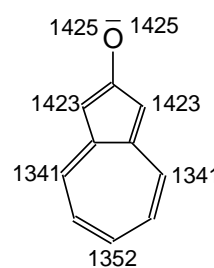

A-2

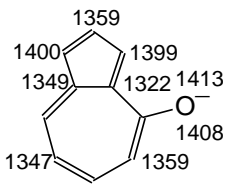

A-3

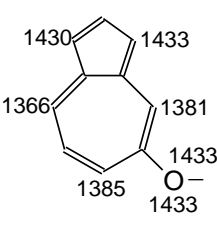

A-4

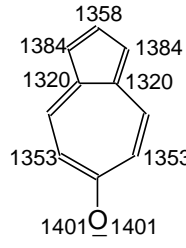

A-5

Figure 4. The DFT-calculated negative protonation energies $\left(-E_{\text {prot }}\right.$, in $\left.\mathrm{kJ} \mathrm{mol}^{-1}\right)$ for deprotonated azulenols. $-E_{\text {prot }}$ for individual conjugated sites placed near $\mathrm{O}$ and $\mathrm{C}$ atoms.

\subsection{Possible Keto and Enol Isomers of Hydroxyazulenes}

Similar to naphthols, hydroxyazulenes ( $\mathrm{OH}$ forms) contain only one labile proton that can move according to the keto-enol prototropic conversion from the exo $\mathrm{OH}$ group to the endo $\mathrm{C}$ atom ( $\mathrm{n}-\pi$ conjugated with the $\mathrm{O}$ atom). As explained above, the number of possible keto $(\mathrm{CH})$ isomers depends on the HO-position in the azulene skeleton and the number of conjugated sites in azulenol. Taking additionally rotation of the exo $\mathrm{OH}$ group about $\mathrm{C}-\mathrm{O}$ bond into account, the following numbers of possible $\mathrm{OH}$ rotamers and $\mathrm{CH}$ isomers 
could be analyzed: ten, seven, nine, seven, and nine for 1- (AH1), 2- (AH2), 4- (AH3), 5(AH4), and 6-hydroxyazulene (AH5), respectively (Figure S1 in Supplementary Materials). Note that for symmetrically substituted derivatives containing $\mathrm{OH}$ at 2- and 6-position, the enol rotamers (AH2a/AH2b and $\mathbf{A H 5 a / A H 5 b ) ~ a n d ~ s o m e ~ k e t o ~ t a u t o m e r s ~ ( A H 2 c / A 2 H d , ~}$ AH2e/AH2f, AH5c/AH5d, AH5f/AH5g, and AH5h/AH5i) have identical constitutional structures. For these azulenols, the number of isomers possessing different structures reduces to four and five, respectively. However, all possible isomers should be considered for estimation of their percentage contents in the isomeric mixtures of AH1-AH5.

Generally, intramolecular proton-transfers in keto-enol prototropic conversions are always accompanied by migration of $n$ - and/or $\pi$-electrons [47]. When an endo $C$ atom in an aromatic system binds the labile proton, it changes its hybridization state from $\mathrm{sp}^{2}$ in the enol isomer to $\mathrm{sp}^{3}$ in the keto form. Consequently, the aromatic ring containing this $\mathrm{C}$ atom can lose its planarity in the keto form. Electron delocalization in the ring and stability of the keto isomer can dramatically change. In the case of naphthols, such kind of structural transformation strongly increases electronic energies of the keto tautomers by more than $30 \mathrm{~kJ} \mathrm{~mol}^{-1}$ at the B3LYP/6-311++G(2df,2p) level when compared to the enol isomers [48], and the keto forms seem to be insignificant in the tautomeric mixtures. They are usually neglected for naphthols. A situation is exceptionally different for isomeric azulenols due to structural differences in the number of $\mathrm{C}$ atoms in the fused rings and the polar character of the azulene skeleton. The polarity of the azulene system (Figure 1) can be considered as some kind of structural factor that facilitates the intramolecular proton-transfers and stabilizes the keto forms.

The atom coordinates and electronic energies $(E)$ for all possible isolated and hydrated structures of neutral AH1-AH5 isomers optimized in vacuo $\{\mathrm{DFT}(\mathrm{B} 3 \mathrm{LYP}) / 6-311 \mathrm{G}(\mathrm{d}, \mathrm{p})\}$ and aqueous solution $\{\mathrm{PCM}($ water $) / / \mathrm{DFT}(\mathrm{B} 3 \mathrm{LYP}) / 6-311 \mathrm{G}(\mathrm{d}, \mathrm{p})\}$ are given in Tables S1 and S2 in Supplementary Materials, respectively. For each derivative (AH1-AH5), perusal of the relative electronic energies $(\Delta E)$ calculated at the DFT level for the keto and enol isomers (Figure 5) show evidently that $\Delta E$ is lower than $20 \mathrm{~kJ} \mathrm{~mol}^{-1}$ at least for one keto isomer (AH1c, AH2c/AH2d, AH3c, AH3e, AH4c, AH4d, and AH5c/AH5d). This means that in the gas phase, the keto form(s) can be found in the isomeric mixtures of AH1-AH5 in a higher amount for 2- and 5-hydroxyazulenes than for the other derivatives. Exceptionally, for 2-hydroxyazulene, the electronic energy of the keto forms AH2c/AH2d is very close to that of the favored enol rotamers $\mathbf{A H 2 a} / \mathbf{A H} 2 \mathbf{b}\left(\Delta E\right.$ ca. $\left.2 \mathrm{~kJ} \mathrm{~mol}^{-1}\right)$. The keto tautomer AH4d of 5-hydroxyazulene has even lower electronic energy than the two enol rotamers AH4a and AH4b $\left(\Delta E<0.5 \mathrm{~kJ} \mathrm{~mol}^{-1}\right)$ and also lower than the other keto form $\mathrm{AH} 4 \mathrm{c}(\Delta E \mathrm{ca}$. $3 \mathrm{~kJ} \mathrm{~mol}^{-1}$ ).

It should be mentioned here that the significant keto tautomers possess the labile proton at the $\mathrm{C} 1, \mathrm{C} 2$, and/or $\mathrm{C} 3$ atom of the azulene five-membered ring. The other keto isomers containing the labile proton at the $\mathrm{C} 4, \mathrm{C} 5, \mathrm{C} 6, \mathrm{C} 7, \mathrm{C} 8, \mathrm{C} 9$, and / or $\mathrm{C} 10$ atom have exceptionally higher electronic energies $\left(25<\Delta E<100 \mathrm{~kJ} \mathrm{~mol}^{-1}\right)$, and they can be neglected in the isomeric mixtures in the gas phase. The differences in stabilities of the $\mathrm{CH}$ forms of the five- and seven-membered rings can be explained by the separation of the positive and negative charge already in the azulene skeleton and the existence of dipole moment, where its negative end is directed toward the five-membered ring [25]. When unsubstituted azulene is protonated in the gas phase, exactly the $\mathrm{C} 1$ atom of the five-membered ring favorably binds the proton. The favored site of protonation has been confirmed by both quantum-chemical calculations and IR spectra measured for protonated azulene by means of infrared multiple photon dissociation (IRMPD) spectroscopy in a Fourier transform ion cyclotron resonance (FT-ICR) mass spectrometer [49]. 


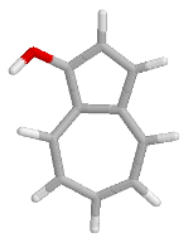

AH1a

$(4.1 ; 4.5)$

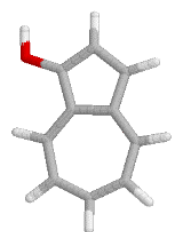

AH1b

$(0.0 ; 0.0)$

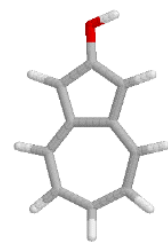

AH2b

$(0.0 ; 0.0)$

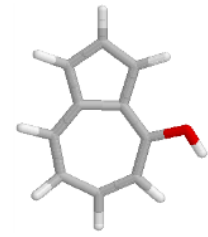

AH3b

$(4.9 ; 0.0)$

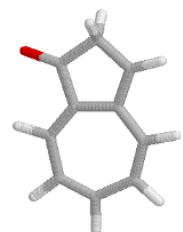

AH1c

(13.4; 27.2)

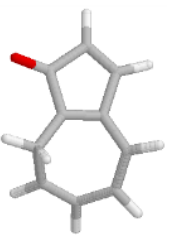

AH1h

(59.0; 74.1)

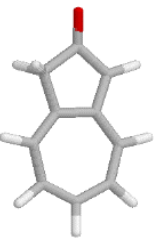

AH2c

$(2.3 ; 1.6)$

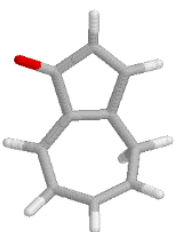

AH1d

(58.7; 74.1)

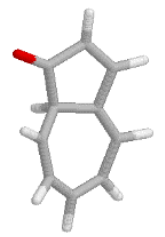

AH1i

(59.0; 40.9)

(a)

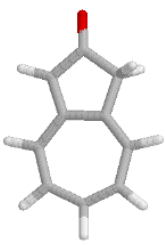

AH2d

$(2.3 ; 1.6)$

(b)

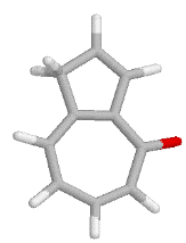

AH3c

$(13.8 ; 15.0)$

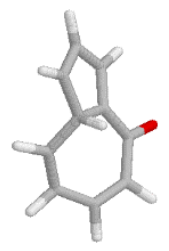

AH3h

(90.8; 93.5)

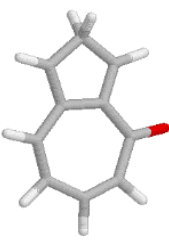

AH3d

(54.4; 61.8)

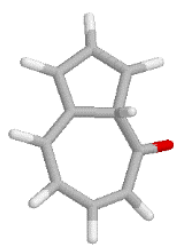

AH3i

(64.7; 70.8)

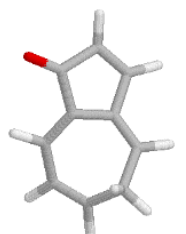

AH1e

$(29.0 ; 37.4)$

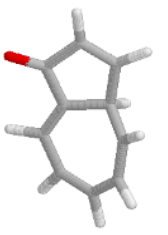

AH1j

$(35.8 ; 27.8)$

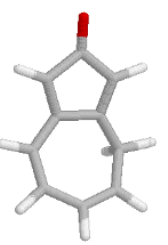

AH2e

(83.9; 95.6)

(83.9; 95.6)

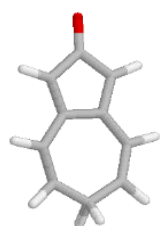

AH2g

(72.8; 81.0)

(c)

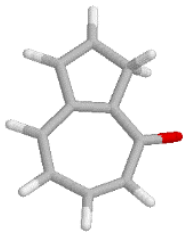

AH3e

$(14.7 ; 16.5)$

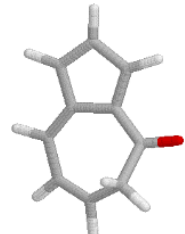

AH3f

(54.3; 61.2)

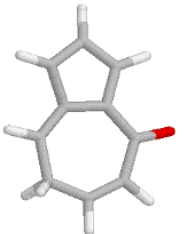

AH3g

(66.3; 67.3)

Figure 5. Cont. 


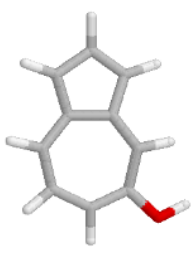

AH4a

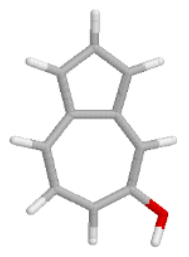

AH4b

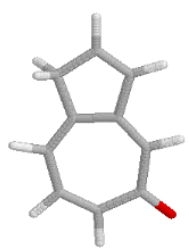

AH4c

$(3.2 ; 2.2)$

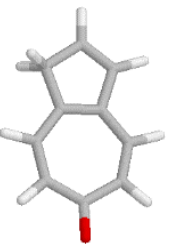

AH5c

(16.4; 17.1)

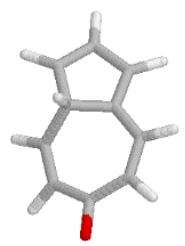

AH5h

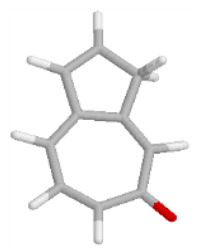

AH4d

$(0.0 ; 0.4)$

(d)

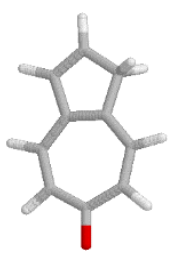

AH5d

$(16.4 ; 17.1)$

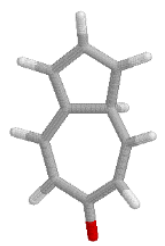

AH5i

$(81.3 ; 86.1)$

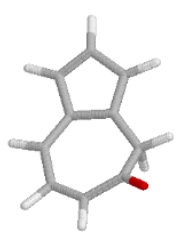

AH4e

(52.0; 65.3)

AH4f

(48.2; 64.0)
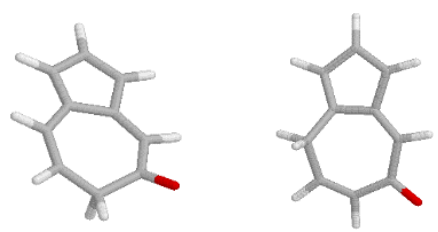

AH4g

$(67.4 ; 79.7)$

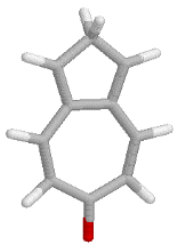

AH5e

(42.6; 51.2)

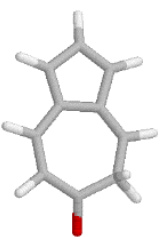

AH5f

$(47.4 ; 57.3)$

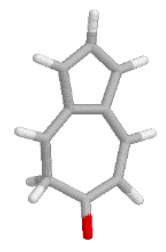

AH5g

(47.4; 57.3)

(81.3; 86.1)

(e)

Figure 5. The structures of enol rotamers and possible keto tautomers of 1- (a), 2- (b), 4- (c), 5- (d), and 6-hydroxyazulene (e), and their relative electronic energies $\left(\Delta E\right.$ given in parentheses, in $\mathrm{kJ} \mathrm{mol}^{-1}$ ) in vacuo (normal style) and aqueous solution (italic style).

In aqueous solution (PCM), the relative electronic energies for possible isomers of AH1-AH5 are not much different from those in vacuo (Figure 5). Bulk solvation does not change the general orders of stabilities of the $\mathrm{OH}$ rotamers and $\mathrm{CH}$ tautomers. Similar to the gas phase, the enol forms predominate in an aqueous solution. Some differences take place for the $\mathrm{OH}$ isomers of 4- (AH3) and 5-hydroxyazulene (AH4). For AH3, the stabilities and relative electronic energies of the $\mathrm{OH}$ rotamers (AH3a and $\mathrm{AH} 3 \mathbf{b}$ ) are reversed in aqueous solution in comparison to those in the gas phase, but both have lower Es than the keto forms (Table S2 in Supplementary Materials). For AH4, four isomers, two enol rotamers (AH4a and AH4b), and two keto tautomers (AH4c and AH4d) are favored in both the gas phase and aqueous solution; however, the orders of their electronic energies slightly differ.

\subsection{Bonds Lengths Alternation in Neutral and Anionic Forms of Hydroxyazulenes}

To understand bond lengths alternation in any azulenol tautomer, we started our analysis from the parent azulene, its valence isomer naphthalene, and their structural aromatic monocyclic parts. Their geometries have been optimized at the same DFT level as that applied for the geometry optimization of AH1-AH5. The structural descriptors (HOMEDs) have been estimated using Equation (1) for the entire molecules and also for 
their cyclic fragments (Figure 6). By definition, HOMED is equal to unity for benzene, for which full $\pi$-electron delocalization with equalization of all CC bond lengths takes place. A structural fusion of the two benzene rings in the naphthalene bicyclic system reduces not only the number of $\mathrm{C}$ atoms and $\pi$-electrons to 10, but it also differentiates the $\mathrm{CC}$ bond lengths, and consequently, decreases $\pi$-electron delocalization. The estimated HOMED values are reduced for the entire naphthalene molecule as well as for its benzene parts, when compared to isolated benzene.

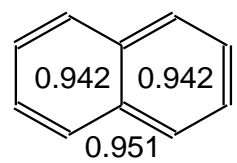

(a)

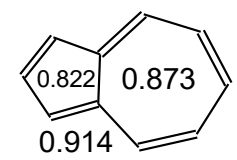

(b)

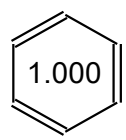

(c)

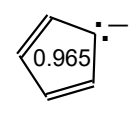

(d)

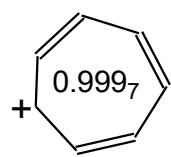

(e)

Figure 6. Comparison of the harmonic oscillator model of electron delocalization (HOMED) indices estimated for the DFT structures of naphthalene (a), azulene (b), and single aromatic rings: benzene (c), cyclopentadiene anion (d), and cycloheptatriene cation (e). HOMEDs for the entire bicyclic molecule placed below structure and those for the single structural parts included in the ring.

Using benzene as the reference molecule in the HOMED procedure, the structural indices have slightly lower values for the cyclopentadiene anion and cycloheptatriene cation (Figure 6), although full equalization of the CC bond lengths occurs for both ions. The decrease of HOMEDs can mainly result from slightly longer CC bonds in the cyclic ions than in neutral benzene. When the cyclopentadiene and cycloheptatriene ions are structurally fused to form the azulene system, the HOMEDs estimated for the individual rings are reduced to a higher degree than those for the benzene parts in naphthalene. Azulene presents weaker $\pi$-electron delocalization than naphthalene. One structural reason is that the $\mathrm{C} 9 \mathrm{C} 10$ bond, common for the two cycles, is considerably longer in azulene $(1.499 \AA)$ than in naphthalene $(1.431 \AA)$. Lower aromatic stability of azulene than naphthalene has also been confirmed by applying other criteria of aromaticity, summarized in ref. [50].

When azulene is substituted by the exo $\mathrm{O}^{-}$group, the HOMED indices vary to a higher degree for $\mathbf{A}^{-} \mathbf{1}-\mathbf{A}^{-} \mathbf{5}$ than for the parent compound. This is a consequence of an additional $n-\pi$ conjugation of the substituent with the azulene system. Exceptionally, for the anions containing the exo $\mathrm{O}^{-}$group at 1- and 2-position of the five-membered ring (data for structures 1 and 2 in Figure 7), the HOMED5 index (estimated for the cyclopentadiene ring, five bonds) strongly decreases from 0.82 for azulene (Figure 6) to 0.64 and 0.62 for $\mathbf{A}^{-1}$ and $\mathbf{A}^{-} \mathbf{2}$, respectively. These variations seem to confirm the intramolecular charge transfer from the seven- to five-membered ring (Figure 1). The repulsion between the negatively charged $\mathrm{O}^{-}$group (acting as a strong electron-donating substituent) and the negatively charged cyclopentadiene ring of the azulene skeleton strongly lengthens the C9C10 bond (up to 1.512 and $1.516 \AA$, respectively). This effect dramatically changes the $\pi$-electrons delocalization and aromatic character of the five-membered ring in $\mathbf{A}^{-\mathbf{1}}$ and $\mathbf{A}^{-}$2. On the other hand, the HOMED5 index increases to 0.90 and 0.93 for $\mathbf{A}^{-} \mathbf{3}$ and $\mathbf{A}^{-} \mathbf{5}$, respectively (data for structures 3 and 5 in Figure 7), for which the exo $\mathrm{O}^{-}$group is linked at 4- and 6-position of the positively charged cycloheptatriene fragment. Note that the C9C10 bond is even shorter for these anions (1.463 and $1.452 \AA$, respectively) than that for the parent azulene, indicating an increase of electron delocalization and aromaticity for the five-membered ring in $\mathbf{A}^{-} \mathbf{3}$ and $\mathbf{A}^{-} \mathbf{5}$. For $\mathbf{A}^{-} \mathbf{4}$, both the $\mathrm{C} 9 \mathrm{C} 10$ bond length (1.496 $⿱$ ) and HOMED5 (0.80) are close to those for azulene.

The other HOMED indices (Figure 7), HOMED7 (0.81-0.88) for the cycloheptatriene ring (seven bonds) and HOMED11s (0.81-0.89) for the azulene skeleton (11 bonds), do not vary so much as HOMED5s when compared to those for the parent system azulene (0.87 and 0.91, respectively, in Figure 6). Generally, they slightly decrease for anions. The HOMED12 indices estimated for the entire molecules, including the CO bond (12 
bonds), are close to HOMED11s and vary from 0.81 to 0.89 . All these HOMED variations shed some light on the distribution of $\pi$-electrons in the azulene skeleton of $\mathbf{A}^{-} \mathbf{1}^{-\mathbf{A}^{-}} \mathbf{5}$.

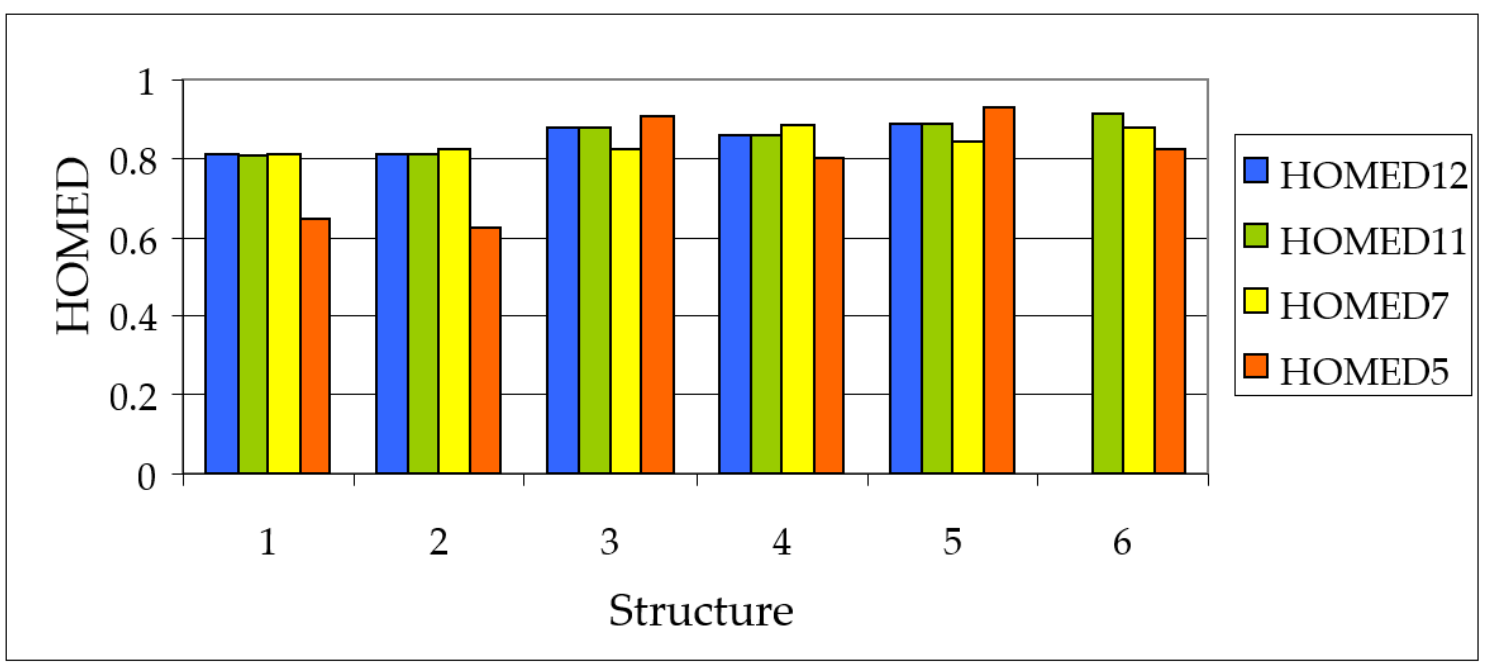

Figure 7. The HOMED indices estimates for unsubstituted azulene (structure 6) and for the five anionic forms $\mathrm{A}^{-1} 1-\mathrm{A}^{-} 5$ (structures 1-5, respectively). HOMED5, HOMED7, HOMED11, and HOMED12 correspond to the five- and sevenmembered rings, azulene system, and the entire molecule containing the $\mathrm{CO}$ bond.

When the exo $\mathrm{O}^{-}$group in the anions $\mathbf{A}^{-} \mathbf{1}^{-} \mathbf{A}^{-} \mathbf{5}$ is protonated and changes to the $\mathrm{OH}$ group in the neutral azulenols AH1-AH5, the electron-donating power of the exo substituent is slightly reduced, and consequently, HOMED5s estimated for the enol rotamers of AH1-AH5 (Table 1) do not vary as much as those for the deprotonated forms $\mathbf{A}^{-} \mathbf{1}-\mathbf{A}^{-} \mathbf{5}$ (Figure 7). However, they change in an analogous way. Interestingly, the $\mathrm{C} 9 \mathrm{C} 10$ bond length seems to be the main factor that dictates the HOMED5 values. Figure 8 presents linear relationships between the HOMED5 indices and C9C10 bond lengths, both estimated at the DFT level for the neutral enol rotamers (correlation coefficient $r=-0.981$ ) and deprotonated anionic forms $(\mathrm{r}=-0.967)$.

Table 1. The HOMED indices estimates at the DFT level for possible enol rotamers of hydroxyazulenes.

\begin{tabular}{ccccc}
\hline Structure & HOMED5 & HOMED7 & HOMED11 & HOMED12 \\
\hline AH1a & 0.803 & 0.855 & 0.902 & 0.861 \\
AH1b & 0.817 & 0.868 & 0.910 & 0.866 \\
AH2a/AH2b & 0.832 & 0.871 & 0.913 & 0.882 \\
AH3a & 0.865 & 0.903 & 0.932 & 0.895 \\
AH3b & 0.852 & 0.896 & 0.928 & 0.888 \\
AH4a & 0.812 & 0.864 & 0.908 & 0.851 \\
AH4b & 0.806 & 0.860 & 0.904 & 0.848 \\
AH5a/AH5b & 0.859 & 0.899 & 0.930 & 0.932 \\
\hline
\end{tabular}

Quite a different situation takes place when the enol forms of AH1-AH5 are transformed during the prototropic conversions into the keto tautomers containing the endo $\mathrm{C}\left(\mathrm{sp}^{3}\right) \mathrm{H}$ and exo $\mathrm{C}=\mathrm{O}$ groups. The HOMED indices for the keto forms decrease (Table 2) in comparison to those for the parent system (Figure 6). In the highest degree, they change for the five- (from 0.23 to 0.79 ) and seven-membered rings (from 0.39 to 0.84 ). Generally, the HOMED5 indices are lower $(<0.55)$ for the keto isomers containing the cyclopentadiene part with the $\mathrm{C}\left(\mathrm{sp}^{3}\right) \mathrm{H}$ and /or $\mathrm{C}=\mathrm{O}$ groups, and they are higher $(>0.6)$ for the keto isomers with these two groups in the cycloheptatriene ring. 


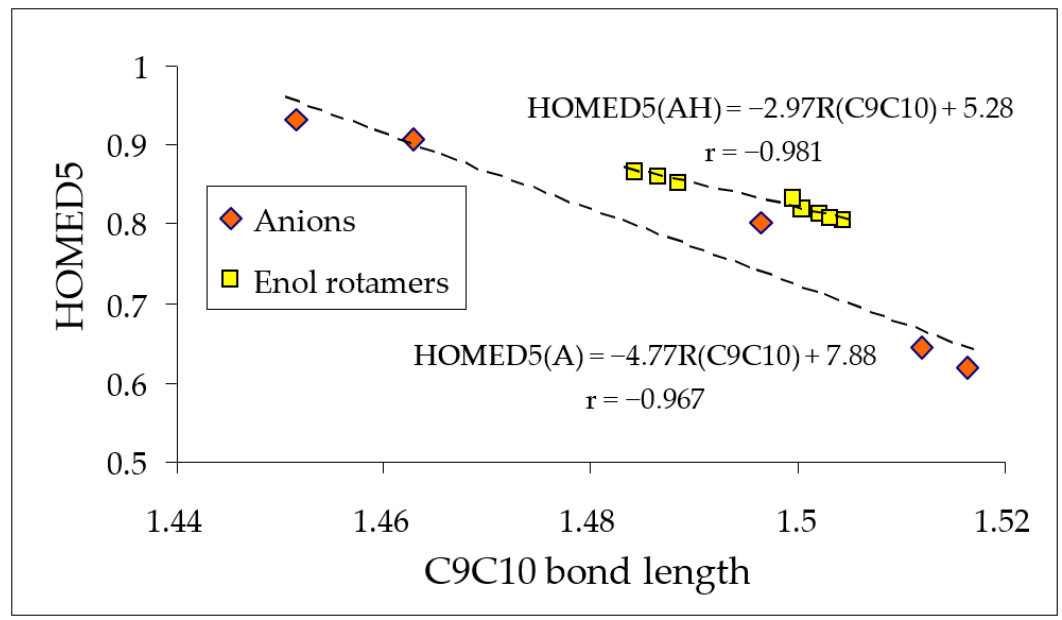

Figure 8. The linear relationships between the DFT-calculated C9C10 bond lengths (in $\AA$ ) and HOMED5 indices for the anion forms and enol rotamers of hydroxyazulenes.

Table 2. The HOMED indices estimates at the DFT level for possible keto $(\mathrm{CH})$ isomers of azulenols.

\begin{tabular}{|c|c|c|c|c|c|}
\hline Isomer & Structure & HOMED5 & HOMED7 & HOMED11 & HOMED12 \\
\hline $\mathrm{C} 1 \mathrm{H} / \mathrm{C} 3 \mathrm{H}$ & $\mathrm{AH} 2 \mathrm{c} / \mathrm{AH} 2 \mathrm{~d}$ & 0.341 & 0.829 & 0.607 & 0.596 \\
\hline $\mathrm{C} 1 \mathrm{H}$ & АH $3 \mathrm{c}$ & 0.504 & 0.835 & 0.652 & 0.650 \\
\hline $\mathrm{C} 3 \mathrm{H}$ & AH3e & 0.519 & 0.831 & 0.657 & 0.656 \\
\hline $\mathrm{C} 1 \mathrm{H}$ & $\mathrm{AH} 4 \mathrm{c}$ & 0.382 & 0.776 & 0.582 & 0.582 \\
\hline $\mathrm{C} 3 \mathrm{H}$ & AH4d & 0.384 & 0.782 & 0.587 & 0.586 \\
\hline $\mathrm{C} 1 \mathrm{H} / \mathrm{C} 3 \mathrm{H}$ & AH5c/AH5d & 0.495 & 0.814 & 0.634 & 0.632 \\
\hline $\mathrm{C} 2 \mathrm{H}$ & AH1c & 0.232 & 0.768 & 0.520 & 0.504 \\
\hline $\mathrm{C} 2 \mathrm{H}$ & AH3d & 0.509 & 0.638 & 0.583 & 0.596 \\
\hline $\mathrm{C} 2 \mathrm{H}$ & AH5e & 0.504 & 0.625 & 0.575 & 0.571 \\
\hline $\mathrm{C} 4 \mathrm{H}$ & AH1d & 0.361 & 0.635 & 0.460 & 0.444 \\
\hline $\mathrm{C} 8 \mathrm{H}$ & AH1h & 0.343 & 0.641 & 0.456 & 0.443 \\
\hline $\mathrm{C} 4 \mathrm{H} / \mathrm{C} 8$ & AH2e/AH2f & 0.341 & 0.829 & 0.607 & 0.596 \\
\hline $\mathrm{C} 4 \mathrm{H}$ & AH4e & 0.670 & 0.446 & 0.525 & 0.515 \\
\hline $\mathrm{C} 8 \mathrm{H}$ & AH4g & 0.637 & 0.424 & 0.504 & 0.501 \\
\hline $\mathrm{C} 5 \mathrm{H}$ & AH1e & 0.473 & 0.523 & 0.467 & 0.457 \\
\hline $\mathrm{C} 7 \mathrm{H}$ & AH1g & 0.484 & 0.521 & 0.473 & 0.462 \\
\hline $\mathrm{C} 5 \mathrm{H}$ & АH $3 \mathrm{f}$ & 0.769 & 0.453 & 0.572 & 0.562 \\
\hline $\mathrm{C} 7 \mathrm{H}$ & AH3g & 0.731 & 0.476 & 0.576 & 0.572 \\
\hline $\mathrm{C} 5 \mathrm{H} / \mathrm{C} 7 \mathrm{H}$ & AH5f/AH5g & 0.774 & 0.459 & 0.572 & 0.564 \\
\hline $\mathrm{C} 6 \mathrm{H}$ & AH1f & 0.374 & 0.626 & 0.454 & 0.440 \\
\hline $\mathrm{C} 6 \mathrm{H}$ & $\mathrm{AH} 2 \mathrm{~g}$ & 0.396 & 0.471 & 0.485 & 0.475 \\
\hline $\mathrm{C} 6 \mathrm{H}$ & AH4f & 0.794 & 0.390 & 0.570 & 0.558 \\
\hline $\mathrm{C} 9 \mathrm{H}$ & AH1i & 0.250 & 0.578 & 0.470 & 0.458 \\
\hline $\mathrm{C} 10 \mathrm{H}$ & AH1j & 0.229 & 0.575 & 0.449 & 0.440 \\
\hline $\mathrm{C} 9 \mathrm{H}$ & AH3h & 0.513 & 0.480 & 0.534 & 0.529 \\
\hline $\mathrm{C} 10 \mathrm{H}$ & AH3i & 0.457 & 0.418 & 0.468 & 0.467 \\
\hline $\mathrm{C} 9 \mathrm{H} / \mathrm{C} 10 \mathrm{H}$ & AH5h/AH5i & 0.461 & 0.425 & 0.473 & 0.318 \\
\hline
\end{tabular}

The lowest HOMED5 values $(\leq 0.25)$ are found for the keto tautomers containing the $\mathrm{C}=\mathrm{O}$ group at 1-position and the labile proton at $\mathrm{C} 2$ (AH1c), $\mathrm{C} 9$ (AH1i), and $\mathrm{C} 10(\mathrm{AH} 1 \mathbf{j})$. The highest HOMED5s (>0.70) are observed for the keto isomers with $\mathrm{C}=\mathrm{O}$ at 4-, 5-, or 6-position and the labile proton at C5 or C7 (AH3f, AH3g, AH5f/AH5g), and C6 (AH4f). Contrary to the deprotonated and enol forms, the $\mathrm{C} 9 \mathrm{C} 10$ bond length is one of the last factors that influence the HOMED5 index for the keto tautomers. On the other hand, the lowest HOMED7 value $(<0.40)$ displays the keto tautomer containing the $\mathrm{C}=\mathrm{O}$ group at 
5-position and the labile proton at $\mathrm{C} 6$ (AH4f). The highest HOMED7 indices ( $>0.80)$ are found for the keto isomers with $\mathrm{C}=\mathrm{O}$ at 2-, 4-, or 6-position and the labile proton at $\mathrm{C} 1$ or C3 (AH2c/AH2d, AH3c, AH3e, AH5c/AH5d), and C4 or C8 (AH2e/AH2f). Note that for some keto isomers, the HOMED5 indices decrease while the HOMED7 values increase. Figure 9 shows linear trends between HOMED5s and HOMED7s for the keto isomers of 1- (AH1) and 5-hydroxyazulenes (AH4). Note that points corresponding to the $\mathrm{C} 9 \mathrm{H}$ and $\mathrm{C} 10 \mathrm{H}$ isomers of $\mathrm{AH} 1$ deviate from this relation, and thus, they have not been included in Figure 9.

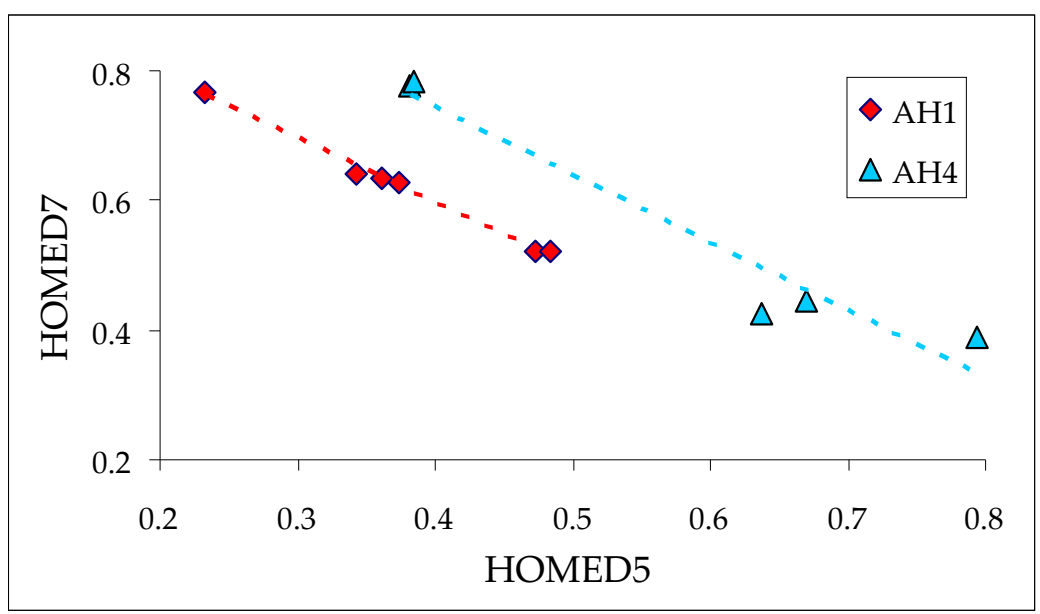

Figure 9. Linear tendencies between the HOMED7 and HOMED5 indices for selected keto isomers of azulenols AH1 and AH4.

Variations of the HOMED11 and HOMED12 indices estimated for the keto tautomers of all azulenols are not so large as those of the HOMED5 and HOMED7 descriptors. Moreover, they change in the same small ranges (from 0.44 to 0.66 ), indicating that the $\mathrm{C}=\mathrm{O}$ group included in the entire molecule ( 12 bonds) does not significantly affect electron delocalization in the azulene system containing 11 bonds. When the HOMED12 values are compared to the relative electronic energies ( $\Delta E$ in Figure 5), both calculated for the keto tautomers optimized at the DFT level, interesting parallelism can be observed for isomers of each derivative, AH1-AH5. These linear tendencies given in Figure 10 shed new light on some kind of symmetry (analogy) between electron delocalization (measured by HOMED) and acid-base properties of the conjugated tautomeric functions (measured by $\Delta E$ ).

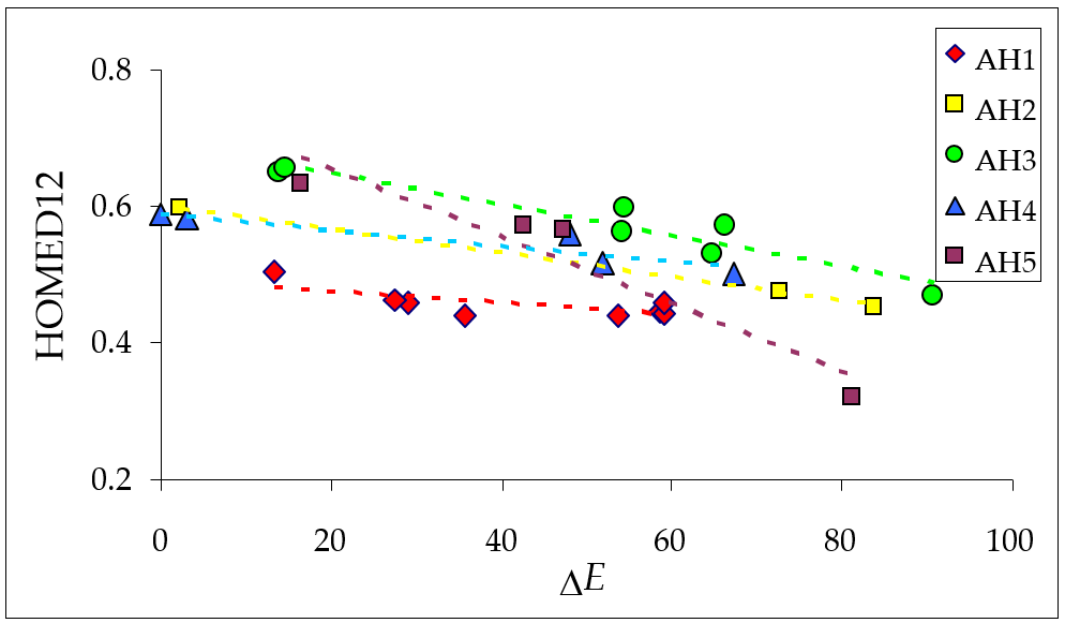

Figure 10. Linear tendencies between the HOMED12 indices and relative electronic energies $(\triangle E$ in $\mathrm{kJ} \mathrm{mol}^{-1}$ ) for all possible keto tautomers of azulenols AH1-AH5. 


\subsection{Favored Isomers for Hydroxyazulenes in Vacuo and Aqueous Solution}

Generally, when the relative electronic (or Gibbs) energies are larger than $20 \mathrm{~kJ} \mathrm{~mol}^{-1}$ for rare tautomers, they participate very little $(<0.01 \%)$ in the tautomeric mixture. Usually, they do not dictate the physicochemical properties of neutral tautomeric systems, and they can be neglected. In the case of azulenols AH1-AH5, all enol OH rotamers (a and $\mathbf{b})$ and at least one keto tautomer $(\mathrm{C} 1 \mathrm{H}, \mathrm{C} 2 \mathrm{H}$, and / or $\mathrm{C} 3 \mathrm{H})$ possess considerably lower electronic energies than the other isomers in vacuo and also in aqueous solution (Figure 5). The relative Gibbs energies for the $\mathrm{OH}$ isomers are not higher than $0.6 \mathrm{~kJ} \mathrm{~mol}^{-1}$ (Table S5 in Supplementary Materials). They can be considered as major forms that consist of tautomeric mixtures. The keto $\mathrm{C} 1 \mathrm{H}$, $\mathrm{C} 2 \mathrm{H}$, and/or $\mathrm{C} 3 \mathrm{H}$ tautomers possessing the relative Gibbs energies lower than $20 \mathrm{~kJ} \mathrm{~mol}^{-1}$ can also participate in the isomeric mixtures. Depending on their percentage contents, estimated using Equation (2), they can be treated as major $(>10 \%)$ or minor $(<10 \%)$ forms. The other $\mathrm{CH}$ tautomers can be considered as rare tautomers $(<0.1 \%)$ or even very rare forms $(<0.01 \%)$ and cannot be considered in the isomeric mixtures of azulenols.

Table 3 summarizes the percentage contents estimated for potential keto and enol isomers that significantly contribute to the tautomeric mixtures of azulenols AH1-AH5 in vacuo and aqueous solution (PCM). For 1-hydroxyazulene (AH1), the enol OH rotamers mainly dictate its physicochemical properties. The contribution of the keto $\mathrm{C} 2 \mathrm{H}$ tautomer is slightly higher in vacuo $(0.3 \%)$ than in aqueous solution $(<0.01 \%)$, but the amounts are very low in both environments. Our results partially confirm the experiments of Asao et al. for AH1 [34], who detected no keto form in ${ }^{1} \mathrm{H}$ NMR spectra recorded in different solvents $\left(\mathrm{CDCl}_{3}, \mathrm{CD}_{2} \mathrm{Cl}_{2}, \mathrm{CD}_{3} \mathrm{CN}\right.$, and also their mixtures with $\left.\mathrm{D}_{2} \mathrm{O}\right)$ and using different temperatures. The amounts of the keto form $\mathrm{C} 2 \mathrm{H}$ in investigated solvents seem to be too low for experimental identification.

Table 3. The percentage contents ( $x$, in \%) estimated for the enol $\mathrm{OH}$ rotamers and selected keto $\mathrm{CH}$ tautomers in the isomeric mixtures of azulenols in vacuo and aqueous solution.

\begin{tabular}{|c|c|c|c|c|c|c|c|}
\hline \multirow{2}{*}{ Structure } & \multirow{2}{*}{ Type of Isomer } & \multicolumn{2}{|c|}{$x$} & \multirow{2}{*}{ Structure } & \multirow{2}{*}{ Type of Isomer } & \multicolumn{2}{|c|}{$x$} \\
\hline & & Gas $^{1}$ & Water $^{2}$ & & & Gas $^{1}$ & Water $^{2}$ \\
\hline AH1a & $\mathrm{OH}(\mathrm{a})$ & 10.1 & 12.4 & AH3e & $\mathrm{C} 3 \mathrm{H}$ & 0.5 & $0.0_{5}$ \\
\hline AH1b & $\mathrm{OH}(\mathrm{b})$ & 89.6 & 87.6 & AH4a & $\mathrm{OH}(\mathrm{a})$ & 28.4 & 33.7 \\
\hline AH1c & $\mathrm{C} 2 \mathrm{H}$ & 0.3 & $0.0_{01}$ & $\mathrm{AH} 4 \mathrm{~b}$ & $\mathrm{OH}(\mathrm{b})$ & 29.0 & 41.9 \\
\hline $\mathrm{AH} 2 \mathrm{a} / \mathrm{AH} 2 \mathrm{~b}$ & $\mathrm{OH}(\mathrm{a}) / \mathrm{OH}(\mathrm{b})$ & 52.8 & 67.9 & $\mathrm{AH} 4 \mathrm{c}$ & $\mathrm{C} 1 \mathrm{H}$ & 9.2 & 7.8 \\
\hline $\mathrm{AH} 2 \mathrm{c} / \mathrm{AH} 2 \mathrm{~d}$ & $\mathrm{C} 1 \mathrm{H} / \mathrm{C} 3 \mathrm{H}$ & 47.2 & 32.1 & AH4d & $\mathrm{C} 3 \mathrm{H}$ & 33.4 & 16.5 \\
\hline АНЗа & $\mathrm{OH}(\mathrm{a})$ & 89.4 & 7.5 & AH5a/AH5b & $\mathrm{OH}(\mathrm{a}) / \mathrm{OH}(\mathrm{b})$ & 99.5 & $99.9_{6}$ \\
\hline AH3b & $\mathrm{OH}(\mathrm{b})$ & 9.5 & 92.4 & AH5c/AH5d & $\mathrm{C} 1 \mathrm{H} / \mathrm{C} 3 \mathrm{H}$ & 0.5 & $0.0_{4}$ \\
\hline $\mathrm{AH} 3 \mathrm{c}$ & $\mathrm{C} 1 \mathrm{H}$ & 0.7 & 0.1 & & & & \\
\hline
\end{tabular}

For 4- (AH3) and 6-hydroxyazulenes (AH5), the situation is only slightly different than that for AH1. Their tautomeric mixtures consist mainly of the enol forms. The contribution of the keto isomers $\mathrm{C} 1 \mathrm{H}$ and $\mathrm{C} 3 \mathrm{H}$ in the isomeric mixture of $\mathrm{AH} 3$ and $\mathrm{AH} 5$ is only slightly higher in the gas phase and in an aqueous solution (PCM) than those of $\mathrm{C} 2 \mathrm{H}$ in AH1. Their small amounts can be identified experimentally. Exceptionally, spectroscopic experiments performed in solution for these derivatives confirmed the presence of the keto isomers [31-33]. Depending on the solvent applied, the keto forms of AH3 and AH5 have been identified on the basis of IR signals for $\mathrm{C}=\mathrm{O}$ bonds and ${ }^{1} \mathrm{H}$ NMR signals for the $\mathrm{CH}_{2}$ group [31-33]. Surprisingly, for $\mathbf{A H 5}$ dissolved in $\mathrm{CDCl}_{3}$, a significant amount (ca. 30\%) has been attributed to the keto form [33].

The situation seems to be completely different for 2- (AH2) and 5-hydroxyazulenes (AH4), for which both the $\mathrm{OH}$ and $\mathrm{CH}$ forms of almost equal amounts participate in the tautomeric mixtures in vacuo. In aqueous solution (PCM), this ratio changes in favor of the enol form; however, the estimated percentage contents of the keto isomers are still very important $(>20 \%)$. To our knowledge, there is no report on the keto-enol tautomerism in 
AH4. However, prototropic conversions have been experimentally confirmed for AH2, which exists in the solvent-dependent keto-enol tautomeric mixture [32]. Analogous relations based on IR and NMR spectra have been observed for other derivatives of azulenols and hydroxyguaiazulenes [31-34]. On the basis of these experiments, some general rule has been formulated that the enol form predominates in solvents acting as hydrogen bond (HB) acceptors (dimethylsulfoxide, 1,4-dioxane, acetone, acetonitrile, etc.), and the keto form can be stabilized in solvents acting as HB donors (dichloromethane, chloroform, methanol) [51].

\subsection{Acid-Base Properties for Selected Isomers and for Isomeric Mixtures}

To our knowledge, acid-base properties for azulenols have not yet been investigated in the gas phase. No documents on measurements or calculations of acid-base parameters can be found in the literature. Only information on $\mathrm{p} K_{\mathrm{a}} \mathrm{s}$ in solution for 2- and 6-hydroxyazulenes has been reported [32]. For these reasons, deprotonation-protonation reaction $\mathbf{A H} \rightleftarrows \mathbf{A}^{-}+\mathrm{H}^{+}$for azulenols has been studied in vacuo. Thermochemical quantities such as enthalpy $(H)$ and Gibbs energy $(G)$ have been calculated for the enol rotamers and selected keto tautomers of AH1-AH5 (Table S4 in Supplementary Materials). Additionally, these quantities have been estimated for the deprotonated forms $\mathbf{A}^{-} \mathbf{1}-\mathbf{A}^{-} \mathbf{5}$ (Table S4 in Supplementary Materials). Using the DFT-calculated $H$ and $G$, acid-base quantities such as proton affinity (PA) and gas-phase basicity (GB) have been determined for all selected major and minor isomers according to Equations (3) and (4), respectively, and summarized in Table 4 . In all cases, the exo $\mathrm{O}^{-}$group in $\mathrm{A}^{-}$displays stronger basicity (higher PAs and GBs) than the endo $\mathrm{HC} 1\left(\mathrm{sp}^{3}\right)^{-}, \mathrm{HC} 2\left(\mathrm{sp}^{3}\right)^{-}$, or $\mathrm{HC} 3\left(\mathrm{sp}^{3}\right)^{-}$groups. In other words, the conjugate exo $\mathrm{OH}$ function in the favored conformation of the enol form has lower acidity than the corresponding endo $\mathrm{H}_{2} \mathrm{C} 1\left(\mathrm{sp}^{3}\right), \mathrm{H}_{2} \mathrm{C} 2\left(\mathrm{sp}^{3}\right)$, or $\mathrm{H}_{2} \mathrm{C} 3\left(\mathrm{sp}^{3}\right)$ group in $\mathrm{AH}$. Note that according to the definition of acid-base quantities in the gas phase $\operatorname{PA}\left(\mathrm{A}^{-}\right)$ $=\Delta_{\text {acid }} H(\mathbf{A H})$ and $\mathrm{GB}\left(\mathbf{A}^{-}\right)=\Delta_{\text {acid }} G(\mathbf{A H})$ [27].

Table 4. The values of acid-base parameters (in $\mathrm{kJ} \mathrm{mol}^{-1}$ at $298 \mathrm{~K}$ ) calculated at the DFT level for selected individual isomers of hydroxyazulenes AH1-AH5.

\begin{tabular}{|c|c|c|c|c|c|c|c|}
\hline Structure & Type of Isomer & $\begin{array}{c}\operatorname{PA}\left(\mathrm{A}^{-}\right)= \\
\Delta_{\mathrm{acid}} H(\mathrm{AH})\end{array}$ & $\begin{array}{c}\mathrm{GB}\left(\mathrm{A}^{-}\right)= \\
\Delta_{\mathrm{acid}} G(\mathrm{AH})\end{array}$ & Structure & Type of Isomer & $\begin{array}{c}\operatorname{PA}\left(\mathrm{A}^{-}\right)= \\
\Delta_{\mathrm{acid}} H(\mathrm{AH})\end{array}$ & $\begin{array}{c}\mathrm{GB}\left(\mathrm{A}^{-}\right)= \\
\Delta_{\mathrm{acid}} G(\mathrm{AH})\end{array}$ \\
\hline AH1a & $\mathrm{OH}(\mathrm{a})$ & 1419.2 & 1385.8 & AH3e & $\mathrm{C} 3 \mathrm{H}$ & 1369.5 & 1339.4 \\
\hline AH1b & $\mathrm{OH}(\mathrm{b})$ & 1420.4 & 1391.2 & AH4a & $\mathrm{OH}(\mathrm{a})$ & 1402.4 & 1370.8 \\
\hline AH1c & $\mathrm{C} 2 \mathrm{H}$ & 1407.2 & 1377.0 & AH4b & $\mathrm{OH}(\mathrm{b})$ & 1402.6 & 1370.9 \\
\hline $\mathrm{AH} 2 \mathrm{a} / \mathrm{AH} 2 \mathrm{~b}$ & $\mathrm{OH}(\mathrm{a}) / \mathrm{OH}(\mathrm{b})$ & 1393.9 & 1362.5 & $\mathrm{AH} 4 \mathrm{c}$ & $\mathrm{C} 1 \mathrm{H}^{\prime}$ & 1398.4 & 1368.0 \\
\hline $\mathrm{AH} 2 \mathrm{c} / \mathrm{AH} 2 \mathrm{~d}$ & $\mathrm{C} 1 \mathrm{H} / \mathrm{C} 3 \mathrm{H}$ & 1391.9 & 1362.2 & AH4d & $\mathrm{C} 3 \mathrm{H}$ & 1401.7 & 1371.2 \\
\hline АH3a & $\mathrm{OH}(\mathrm{a})$ & 1383.1 & 1352.3 & AH5a/AH5b & $\mathrm{OH}(\mathrm{a}) / \mathrm{OH}(\mathrm{b})$ & 1371.0 & 1339.3 \\
\hline AH3b & $\mathrm{OH}(\mathrm{b})$ & 1378.3 & 1346.7 & AH5c/AH5d & $\mathrm{C} 1 \mathrm{H} / \mathrm{C} 3 \mathrm{H}$ & 1355.3 & 1326.0 \\
\hline AH3c & $\mathrm{C} 1 \mathrm{H}$ & 1370.1 & 1340.1 & & & & \\
\hline
\end{tabular}

For estimations of the PA/ $\Delta_{\text {acid }} H$ and GB/ $\Delta_{\text {acid }} G$ values for the isomeric mixtures of azulenols AH1-AH5, the percentage contents of the potential enol rotamers and keto tautomers (Table 3) have been employed. Table 5 summarizes the values of gas-phase acid-base parameters estimated for the deprotonation-protonation reaction of the major and minor isomers of AH1-AH5 to their common anion $\mathbf{A}^{-} \mathbf{1}_{-}^{-\mathbf{A}^{-}} \mathbf{5}$. We can see that in the case when the percentage contents of the keto isomers are very low (Table 3 ), the $\mathrm{PA} / \Delta_{\text {acid }} H$ and GB $/ \Delta_{\text {acid }} G$ values estimated for the isomeric mixture (Table 5) are close to those for the favored enol isomer (Table 4). Such a type of situation takes place for three hydroxyazulenes: AH1, AH3, and AH5. However, when the enol rotamers and the keto tautomers participate in the isomeric mixture in almost equal amounts, the values of $\mathrm{PA} / \Delta_{\text {acid }} H$ and $\mathrm{GB} / \Delta_{\text {acid }} G$ determined for the isomeric mixture are between those found for the enol and keto tautomers. This case concerns the azulenol AH2 and also AH4. 
Table 5. The values of acid-base parameters (in $\mathrm{kJ} \mathrm{mol}^{-1}$ at $298 \mathrm{~K}$ ) estimated for the mixtures of major and minor isomers of hydroxyazulenes AH1-AH5.

\begin{tabular}{|c|c|c|c|c|c|}
\hline Compound & $\begin{array}{l}\text { Mixture of the Favored Isomers } \\
\text { for Neutral AH (Acid) }{ }^{1}\end{array}$ & $\begin{array}{l}\text { Anion } A^{-} \\
\text {(Base) }^{2}\end{array}$ & $\begin{array}{c}\text { PA or } \\
\Delta_{\text {acid }} H\end{array}$ & $\begin{array}{l}\text { GB or } \\
\Delta_{\text {acid }} G\end{array}$ & Ref. \\
\hline 1-Azulenol & $\mathrm{AH} 1 \mathrm{a} \rightleftarrows \mathrm{AH} 1 \mathrm{~b} \rightleftarrows \mathrm{AH} 1 \mathrm{c}$ & $A^{-1}$ & 1420.3 & 1390.6 & 3 \\
\hline 2-Azulenol & $\mathrm{AH} 2 \mathrm{a} / \mathrm{AH} 2 \mathrm{~b} \rightleftarrows \mathrm{AH} 2 \mathrm{c} / \mathrm{AH} 2 \mathrm{~d}$ & $A^{-2}$ & 1393.0 & 1362.3 & 3 \\
\hline 4-Azulenol & $\mathrm{AH} 3 \mathrm{a} \rightleftarrows \mathrm{AH} 3 \mathrm{~b} \rightleftarrows \mathrm{AH} 3 \mathrm{c} \rightleftarrows \mathrm{AH} 3 \mathrm{e}$ & $A^{-3}$ & 1382.5 & 1351.6 & 3 \\
\hline 5-Azulenol & $\mathrm{AH} 4 \mathrm{a} \rightleftarrows \mathrm{AH} 4 \mathrm{~b} \rightleftarrows \mathrm{AH} 4 \mathrm{c} \rightleftarrows \mathrm{AH} 4 \mathrm{~d}$ & $A^{-4}$ & 1401.8 & 1370.7 & 3 \\
\hline 6-Azulenol & AH5a/AH2b $\rightleftarrows$ AH5c/AH5d & $A^{-5}$ & 1370.9 & 1339.2 & 3 \\
\hline 2-Naphthol ${ }^{4}$ & & & 1438 & 1408 & 5 \\
\hline Phenol ${ }^{4}$ & & & 1462 & 1432 & 5 \\
\hline
\end{tabular}

${ }^{1}$ Structures given in Figure $5 .{ }^{2}$ Structures given in Figure $4 .{ }^{3}$ This work. ${ }^{4}$ The keto tautomers can be neglected in the isomeric mixture [48]. ${ }^{5}$ Experimental data taken from ref. [27].

It should be mentioned here that when the exo $\mathrm{OH}$ group is at 6-position in the seven-membered ring, hydroxyazulene displays the strongest acidity. It has the lowest PA and GB for the isomeric mixture (Table 5). This suggests that an electron-accepting effect of the five-membered ring affects the 6-position to a higher degree than positions 4 (or 8 ) and 5 (or 7). Generally, acidity of hydroxyazulenes decreases in the following order: AH5 > AH3 > AH2 > AH4 > AH1. 1-hydroxyazulene is the weakest acid in the series. It possesses the highest PA and GB for the isomeric mixture. All these PA and GB values for isomeric mixtures of AH1-AH5 can be compared with those reported for other hydroxy arenes such as 2-naphthol and phenol [27], also included in Table 5. Note that there are no acid-base data for 1-naphthol in ref. [27]. The comparison shows that all hydroxyazulenes studied here, even 1-hydroxyazulene, are stronger acids in the gas phase than naphthols and phenol. This can result from high polarizability of the azulene skeleton. Analogous order of acidity is found on the basis of the $\mathrm{p} K_{\mathrm{a}}$ values determined in the solution for 2- (AH2) and 6-hydroxyazulene (AH5) when they have been compared to phenol and naphthols [32].

\section{Conclusions}

On the basis of our quantum-chemical calculations carried out for hydroxyazulenes in vacuo and aqueous solution, we can conclude that the choice of computational-chemistry methods is a suitable way for testing the keto forms in polycyclic and well delocalized hydroxy arenes. These methods give the possibility to identified not only the major and minor isomers but also the rare and very rare keto forms (Figure 5), which cannot be found by experimental techniques. They can help to shed some light on factors that dictate stabilities and electron delocalization of the keto and enol forms. They can also make it possible to formulate some analogies between energetic and structural parameters for tautomeric systems. Additionally, using these methods, we can estimate microscopic and macroscopic acid-base properties for individual isomers as well as for the tautomeric mixtures, respectively.

An application of the HOMED index for quantitative measurements of the bond lengths alternation in the azulene skeleton and in its individual rings gives additional information on electron delocalization in investigated non-benzenoid systems. When proceeding from the enol isomers to keto forms, the labile proton-transfer from the exo $\mathrm{OH}$ group to the endo $C$ atom decreases not only the stability of the keto isomers but also electron delocalization (measured by HOMED). The highest HOMED variations occur for the five- and seven-membered rings when the $C$ atom changes its hybridization state from $\mathrm{C}$-sp ${ }^{2}$ in the enol isomer to C-sp ${ }^{3}$ in the keto form (Table 2). 
Generally, a high amount of the keto isomers is not related to the molecule symmetry but with the polarity of the azulene skeleton and acid-base properties of the endo $C$ sites that are $n-\pi$ conjugated with the exo substituent. These two factors affect both the relative energies $(\Delta E)$ and electron delocalization (HOMED) of the keto forms that some parallelism of their variations observed (Figure 10). Exceptional stabilities of some keto forms dictate additional physicochemical properties of the azulene derivatives, such as acid-base properties of the tautomeric mixtures (Table 5).

Among the five azolenols (AH1-AH5) investigated here, two of them (symmetrically substituted 2-hydroxyazulene AH2 and unsymmetrically substituted 5-hydroxy derivative AH4) are the most interesting keto-enol systems (Scheme 1). In vacuo (non-polar environment), their keto and enol forms exist in almost equal amounts in the tautomeric mixture. The tautomers $\mathrm{C} 1 \mathrm{H}$ and $\mathrm{C} 3 \mathrm{H}$ are more favored than the other $\mathrm{CH}$ forms. Solvent (aqueous solution modeled by the PCM theory) seems to affect tautomeric equilibria and change the amount-ratio of the keto and enol forms in favor of the enol isomers. For the other three azulenols (AH1, AH3, and AH5), the enol forms consist mainly of the isomeric mixtures $(>99 \%)$ in the two environments. Only small quantities of the $\mathrm{CH}$ isomers can be identified in vacuo $(<2 \%)$ or aqueous solution $(<0.2 \%)$.

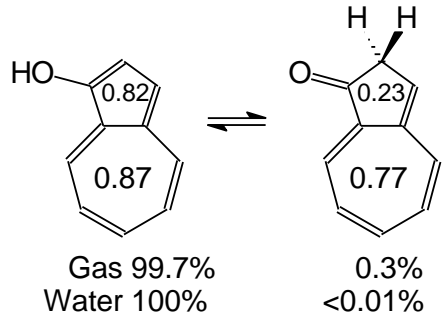

(a)

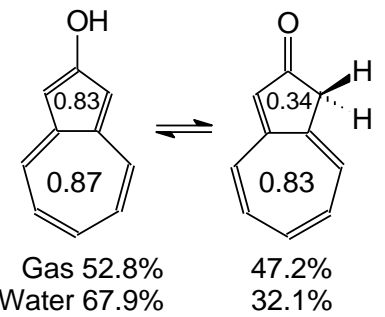

(b)

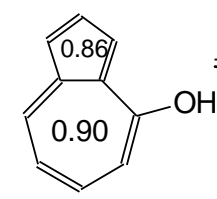

Gas $98.8 \%$

Water $99.9 \%$
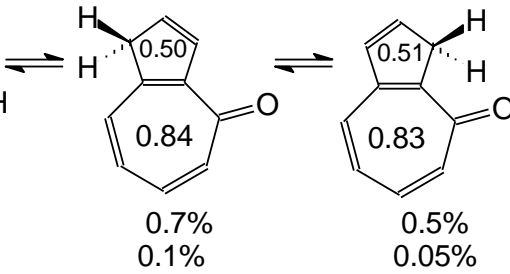

(c)

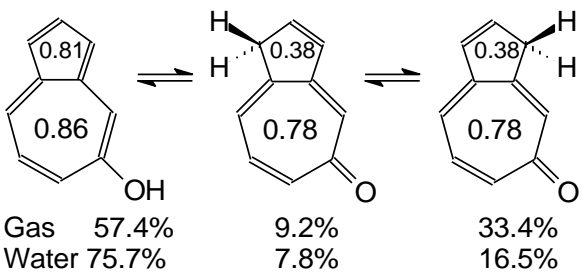

(d)

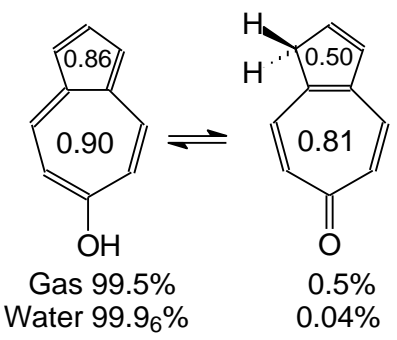

(e)

Scheme 1. The favored keto and enol tautomers for 1- (a), 2- (b), 4- (c), 5- (d), and 6-hydroxyazulene (e). HOMED5s and HOMED7s are placed in the rings. The percentages contents of isomers in vacuo and aqueous solution are included below structures.

Supplementary Materials: The following are available online at https:/ /www.mdpi.com/2073-8 994/13/3/497/s1, Figure S1: The Lewis structures of all possible neutral isomers of investigated azulenols, Table S1: The atom coordinates for all possible isolated and hydrated structures of neutral isomers of investigated azulenols optimized in vacuo and aqueous solution, Table S2: The electronic 
energies for all possible isolated and hydrated structures of neutral isomers of azulenols calculated in vacuo and aqueous solution, Table S3: The atom coordinates for five anion structures of azulenols optimized in vacuo and their DFT-calculated electronic energies, Table S4: The enthalpies and Gibbs energies calculated in vacuo for selected neutral isomers of azulenols and their anions, Table S5: The relative Gibbs energies calculated for selected neutral isomers of azulenols in vacuo and aqueous solution, PCM parameters.

Funding: This research received no external funding.

Institutional Review Board Statement: Not applicable.

Informed Consent Statement: Not applicable.

Data Availability Statement: Supplementary Materials.

Acknowledgments: The author dedicates this work to the students of the Biology Department (SGGW, Warsaw) who were particularly interested in non-benzenoic aromatic derivatives.

Conflicts of Interest: The author declares no conflict of interest.

\section{References}

1. Murfin, L.C.; Lewis, S.E. Azulene-A bright core for sensing and imaging. Molecules 2021, 26, 353. [CrossRef] [PubMed]

2. Ito, S.; Morita, N. Creation of stabilized electrochromic materials by taking advantage of azulene skeletons. Eur. J. Org. Chem. 2009, 2009, 4567-4579. [CrossRef]

3. Shoji, T.; Ito, S. Azulene-based donor-acceptor systems: Synthesis, optical, and electrochemical properties. Chem. Eur. J. 2017, 23, 16696-16709. [CrossRef]

4. Xin, H.; Gao, X. Application of azulene in constructing organic optoelectronic materials: New tricks for an old dog. ChemPlusChem 2017, 82, 945-956. [CrossRef]

5. Pirzad, A.; Alyari, H.; Shakiba, M.R.; Zehtab-Salmasi, S.; Mohammadi, A. Essential oil content and composition of German chamomile (Matricaria chamomilla L.) at different irrigation regimes. J. Agron. 2006, 5, 451-455. [CrossRef]

6. Németh, E. Essential oil composition of species in the genus Achillea. J. Essent. Oil Res. 2005, 17, 501-512. [CrossRef]

7. Vasylievna, Z.S.; Erdemovna, R.T.; Dorzhievna, R.L.; Arnoldovich, A.; Long, C.S.; Gao, Q.B.; Qi, Z.F. Comparative studies on composition of essential oil in three wormwoods (Artemisia L.) from Buryatia and Mongolia. J. Essent. Oil Bear. Plants 2015, 18, 637-641. [CrossRef]

8. Tala, M.T.; Qin, J.; Ndongo, J.T.; Laatsch, H. New Azulene-type sesquiterpenoids from fruiting bodies of Lactarius delicious. Nat. Prod. Bioprospect. 2017, 7, 269-273. [CrossRef] [PubMed]

9. Pereira, D.M.; Valentao, P.; Andrade, P.B. Marine natural pigments: Chemistry, distribution and analysis. Dye. Pigment. 2014, 111, 124-134. [CrossRef]

10. Liu, R.S.H.; Asato, A.E. Tuning the color and excited state properties of the azulenic chromophore: NIR absorbing pigments and materials. J. Photochem. Photobiol. C Photochem. Rev. 2003, 4, 179-194. [CrossRef]

11. Murai, M.; Ku, S.-Y.; Treat, N.D.; Robb, M.J.; Chabinyc, M.L.; Hawker, C.J. Modulating structure and properties in organic chromophores: Influence of azulene as a building block. Chem. Sci. 2014, 5, 3753-3760. [CrossRef]

12. McKay, D.L.; Blumberg, J.B. A review of the bioactivity and potential health benefits of chamomile tea (Matricaria recutita L.). Phytother. Res. 2006, 20, 519-530. [CrossRef]

13. Peet, J.; Selyutina, A.; Bredihhin, A. Antiretroviral (HIV-1) activity of azulene derivatives. Bioorg. Med. Chem. 2016, $24,1653-1657$. [CrossRef]

14. Ueki, J.-I.; Sakagami, H.; Wakabayashi, H. Anti-UV activity of newly-synthesized water-soluble azulenes. Vivo 2013, 27, 119-126.

15. Murafuji, T.; Kitagawa, K.; Yoshimatsu, D.; Kondo, K.; Ishiguro, K.; Tsunashima, R.; Miyakawa, I.; Mikata, Y. Heterocyclic bismuth carboxylates based on a diphenyl sulfone scaffold: Synthesis and antifungal activity against Saccharomyces cerevisiae. Eur. J. Med. Chem. 2013, 63, 531-535. [CrossRef] [PubMed]

16. Wada, T.; Maruyama, R.; Irie, Y.; Hashimoto, M.; Wakabayashi, H.; Okudaira, N.; Uesawa, Y.; Kagaya, H.; Sakagami, H. In vitro anti-tumor activity of azulene amide derivatives. Vivo 2018, 32, 479-486. [CrossRef]

17. Ayaz, F.; Yuzer, A.; Ince, T.; Ince, M. Anti-cancer and anti-inflammatory activities of bromo- and cyano-substituted azulene derivatives. Inflammation 2020, 43, 1009-1018. [CrossRef]

18. Szopa, A.; Pajor, J.; Klin, P.; Rzepiela, A.; Elansary, H.O.; Al-Mana, F.A.; Mattar, M.A.; Ekiert, H. Artemisia absinthium L.-Importance in the history of medicine, the latest advances in phytochemistry and therapeutical, cosmetological and culinary uses. Plants 2020, 9, 1063. [CrossRef] [PubMed]

19. Barić, D. Utilizing the azaazulene scaffolds in the design of new organic superbases. ACS Omega 2019, 4, 15197-15207. [CrossRef] [PubMed]

20. Schmitt, S.; Baumgarten, M.; Simon, J.; Hafner, K. 2,4,6,8-Tetracyanoazulene: A new building block for "organic metals". Angew. Chem. Int. Ed. 1998, 37, 1077-1081. [CrossRef] 
21. Mori, A.; Yokoo, M.; Hashimoto, M.; Ujiie, S.; Diele, S.; Baumeister, U.; Tschierske, C. A novel biaxial smectic liquid crystalline phase formed by rodlike molecules with a 1,3-diazaazulene skeleton. J. Am. Chem. Soc. 2003, 125, 6620-6621. [CrossRef]

22. Tang, T.; Lin, T.; Wang, F.; He, C. Azulene-based conjugated polymers with tuneable near-IR absorption up to $2.5 \mu \mathrm{m}$. Polym. Chem. 2014, 5, 2980-2989. [CrossRef]

23. Lacroix, P.G.; Malfant, I.; Iftime, G.; Razus, A.C.; Nakatani, K.; Delaire, J.A. Azo-azulene derivatives as second-order nonlinear optical chromophores. Chem. Eur. J. 2000, 6, 2599-2608. [CrossRef]

24. Xin, X.S.; Ge, C.W.; Jiao, X.C.; Yang, X.D.; Rundel, K.; McNeill, C.R.; Gao, X.K. Incorporation of 2,6-connected azulene units into the backbone of conjugated polymers: Towards high-performance organic optoelectronic materials. Angew. Chem. Int. Ed. 2018, 57, 1322-1326. [CrossRef] [PubMed]

25. Dittrich, B.; Fabbiani, F.P.A.; Henn, J.; Schmidt, M.U.; Macchi, P.; Meindl, K.; Spackman, M.A. Azulene revisited: Solid-state structure, invariom modeling and lattice-energy minimization of a classical example of disorder. Acta Crystallogr. B 2018, 74, 416-426. [CrossRef]

26. Huber, S.; Grassi, G.; Bauder, A. Structure and symmetry of azulene as determined from microwave spectra of isotopomers. Mol. Phys. 2005, 103, 1395-1409. [CrossRef]

27. NIST Chemistry WebBook. NIST Standard Reference Database No. 69; Linstrom, P.J., Mallard, W.G., Eds.; National Institute of Standards and Technology: Gaithersburg, MD, USA, 2014. Available online: http:/ / webbook.nist.gov/chemistry (accessed on 20 February 2021).

28. Gal, J.-F.; Maria, P.-C.; Decouzon, M.; Mó, O.; Yanez, M.; Abboud, J.L.A. Lithium-cation/ $\pi$ complexes of aromatic systems. The effect of increasing the number of fused rings. J. Am. Chem. Soc. 2003, 125, 10394-10401. [CrossRef] [PubMed]

29. Mąkosza, M.; Podraza, R. Hydroxylation and amination of azulenes by vicarious nucleophilic substitution of hydrogen. Eur. J. Org. Chem. 2000, 2000, 193-198. [CrossRef]

30. Yokoyama, R.; Ito, S.; Okujima, T.; Kubo, T.; Yassunami, M.; Tajiri, A.; Morita, N. Synthesis of 2-aminoazulene derivatives. Nucleophilic and palladium-catalyzed amination of 2-substituted azulene. Tetrahedron 2003, 59, 8191-8198. [CrossRef]

31. Hafner, K.; Kaiser, H. Zur kenntnis der azulene. 3. Eine einfache synthese substituierter azulene. Justus Liebigs Ann. Chem. 1958, 618, 140-152. [CrossRef]

32. Takase, K.; Asao, T.; Takagi, Y.; Nozoe, T. Syntheses and some properties of 2- and 6-hydroxyazulenes. J. Chem. Soc. Chem. Commun. 1968, 368b-370. [CrossRef]

33. Morita, T.; Kanzawa, H.; Takase, K. The synthesis and some properties of 2,6-dihydroxyazulene. Chem. Lett. 1977, 6, 753-756. [CrossRef]

34. Asao, T.; Ito, S.; Morita, N. 1-Hydroxyazulene and 3-hydroxyguaiazulene: Synthesis and their properties. Tetrahedron Lett. 1989, 30, 6693-6696. [CrossRef]

35. Parr, R.G.; Yang, W. Density Functional Theory of Atoms and Molecular Orbital Theory; Oxford University Press: New York, NY, USA, 1989.

36. Becke, A.D. Density-functional thermochemistry. III. The role of exact exchange. J. Chem. Phys. 1993, 98, 5648-5652. [CrossRef]

37. Lee, C.; Yang, W.; Parr, R.G. Development of the colle-salvetti correlation-energy formula into a functional of the electron density. Phys. Rev. B 1988, 37, 785-789. [CrossRef]

38. Hehre, W.J.; Radom, L.; Schleyer, P.v.R.; Pople, J.A. Ab Initio Molecular Theory; Wiley: New York, NY, USA, 1986.

39. Miertus, S.; Tomasi, J. Approximate evaluation of the electrostatic free energy and internal energy changes in solution processes. Chem. Phys. 1982, 65, 239-245. [CrossRef]

40. Miertus, S.; Scrocco, E.; Tomasi, J. Electrostatic interaction of a solute with a continuum. A direct utilization of ab initio molecular potentials for the prevision of solvent effects. Chem. Phys. 1981, 55, 117-129. [CrossRef]

41. Raczyńska, E.D.; Makowski, M.; Zientara-Rytter, K.; Kolczyńska, K.; Stępniewski, T.M.; Hallmann, M. Quantum-chemical studies on the favored and rare tautomers of neutral and redox adenine. J. Phys. Chem. A 2013, 117, 1548-1559. [CrossRef]

42. Raczyńska, E.D.; Kamińska, B. Variations of the tautomeric preferences and $\pi$-electron delocalization for the neutral and redox forms of purine when proceeding from the gas phase (DFT) to water (PCM). J. Mol. Model. 2013, 19, 3947-3960. [CrossRef] [PubMed]

43. Frisch, M.J.; Trucks, G.W.; Schlegel, H.B.; Scuseria, G.E.; Robb, M.A.; Cheeseman, J.R.; Montgomery, J.A., Jr.; Vreven, T.; Kudin, K.N.; Burant, J.C.; et al. Gaussian-03, Revision E.01; Gaussian, Inc.: Wallingford, CT, USA, 2004.

44. Raczyńska, E.D. Application of the extended HOMED (Harmonic Oscillator Model of Aromaticity) index to simple and tautomeric five-membered heteroaromatic cycles with C, N, O, P, and S atoms. Symmetry 2019, 11, 146. [CrossRef]

45. Kruszewski, J.; Krygowski, T.M. Definition of aromaticity basing on the harmonic oscillator model. Tetrahedron Lett. 1972, 13, 3839-3842. [CrossRef]

46. Fifen, J.J.; Dhaouadi, Z.; Nsangou, M. Revision of the thermodynamics of the proton in the gas phase. J. Phys. Chem. A 2014, 118, 11090-11097. [CrossRef] [PubMed]

47. Pauling, L. The Nature of the Chemical Bond, 3rd ed.; Cornel University Press: New York, NY, USA, 1960.

48. Ośmiałowski, B.; Raczyńska, E.D.; Krygowski, T.M. Tautomeric equilibria and pi electron delocalization for some monohydroxyarenes-quantum chemical studies. J. Org. Chem. 2006, 71, 3727-3736. [CrossRef] [PubMed]

49. Zhao, D.; Langer, J.; Oomens, J.; Dopfer, O. Infrared spectra of protonated polycyclic aromatic hydrocarbon molecules: Azulene. J. Chem. Phys. 2009, 131, 184307. [CrossRef] [PubMed] 
50. Krygowski, T.M.; Zachara, J.E. Geometry-based analysis of azulene and azulene-like systems with H- or Li-bonding. J. Phys. Org. Chem. 2007, 20, 594-599. [CrossRef]

51. Reichardt, C. Solvent Effects in Organic Chemistry; Verlag Chemie GmbH: Weinheim, Germany, 1979. 